Revista de Estudios Histórico-Jurídicos

[Sección Derecho Romano]

XXXVI (Valparaíso, Chile, 2014)

[pp. 189 - 223]

\title{
AdquiSICIONES ESTIPULATORIAS \\ REALIZADAS POR EL "SERVUS FRUCTUARIUS"
}

[Acquisitions by Way of Stipulations Carried out by the "servus fructuarius"]

\author{
María José Torres Parra*
}

Universidad Complutense de Madrid, España

\section{RESUMEN}

El trabajo examina los problemas que plantean las estipulaciones celebradas por un servus fructuarius, con especial referencia a las circunstancias que determinan $y$, en su caso, alteran el régimen general de adquisición.

\section{Palabras clave}

Estipulaciones del servus fructuarius Actio ex stipulatu.

\section{Abstract}

This work examines the problems arising from the stipulations entered into by a servus fructuarius, specially focused on the circumstances that determine and, in this case, modify the general acquisition regime.

\section{KeYwords}

Stipulations of the servus fructuarius Actio ex stipulatu.

ReCibIDO el 10 de octubre de 2013 y ACEPTADO 26 de julio de 2014

* Profesora titular de derecho romano en la Facultad de Derecho de la Universidad Complutense de Madrid. Correo electrónico: mjtorres@ucm.es 


\section{Planteamiento general de las adquisiciones A TRAVÉS DEL “SERVUS FRUCTUARIUS”}

Objeto central de este trabajo es el régimen aplicable a las estipulaciones realizadas por un esclavo sobre el que grava un derecho de usufructo, es decir, el servus fructuarius. Para enmarcar el tema específico que interesa, parece conveniente recordar previamente unas ideas generales sobre las adquisiciones del servus fructuarius con independencia de su participación en un negocio estipulatorio.

A las adquisiciones en general se refiere Gai. 2,86 [= D. 41,1,10 pr. (Gai. 2 inst.) = Inst. 2,9 pr.]: “Adquiritur ${ }^{1}$ autem $^{2}$ nobis non solum per nosmet ipsos, sed etiam per eos, quos in potestate manu mancipiove $e^{3}$ habemus: item per eos ${ }^{4}$ servos, in quibus usumfructum habemus; item per homines liberos et servos alienos, quos bona fide possidemus: de quibus singulis diligenter ${ }^{5}$ dispiciamus".

Gayo se limita a recordar la posibilidad de adquirir no sólo por nosotros mismos, sino también por medio de quienes están bajo la patria potestas del paterfamilias, la manus del marido, o in mancipio. En el caso del usufructuario, puede éste realizar adquisiciones a través del esclavo sobre el que tiene el usufructo. Tras esta declaración general, Gayo anuncia un tratamiento más detallado de la cuestión en epígrafes posteriores.

Efectivamente, tal como había anunciado en el pasaje reproducido, vuelve después sobre el tema en Gai 2,91 [= D. 41,1,10,3-4 (Gai., 2 inst.) = Inst. 2,9,4].

Comencemos con Gai. 2,91: "De his autem servis, in quibus tantum usumfructum habemus ${ }^{6}$, ita placuit, ut quidquid ex re nostra ${ }^{7}$ vel ex operis ${ }^{8}$ suis adquirunt, id nobis ${ }^{10}$ adquiratur ${ }^{11}$; quod ${ }^{12}$ vero ex extra eas causas ${ }^{13}$ id ad dominum proprietatis pertineat ${ }^{14}$ : itaque si iste ${ }^{15}$ servus heres institutus sit legatumve quid ei aut donatum ${ }^{16}$ fuerit, non mihi ${ }^{17}$, sed domino proprietatis adquiritur".

En la primera parte del fragmento, Gayo recuerda la regla de a quién corresponde lo adquirido con bienes cuya propiedad pertenece al titular del derecho de usufructo sobre el servus: será el usufructuario quien adquiera; así mismo, también corresponderá a éste lo adquirido por el servus fructuarius con sus pro-

\footnotetext{
${ }^{1}$ Adquiruntur en D.

${ }^{2}$ Suprimen autem D. e Inst.

${ }^{3}$ Omite manu mancipiove D.

${ }^{4}$ Omite eos D.

${ }^{5}$ Diligentius en D.

${ }^{6}$ Habetis en Inst.

${ }^{7}$ Vestra en Inst.

${ }^{8}$ Operibus en Inst.

${ }^{9}$ Adquirant en D. y en Inst.

${ }^{10}$ Vobis en Inst.

${ }^{11}$ Adiciatur en Inst.

${ }^{12}$ Si quid en D.

${ }^{13}$ Persecuti sint en D. y en Inst.

${ }^{14}$ Pertinet en D.

${ }^{15}$ Is en D.

${ }^{16}$ Quid aut ei donatum en D.

${ }^{17}$ Usufructuario en Inst.
} 
pias operae ${ }^{18}$. Añadiendo a continuación que lo adquirido extra eas causas, es del nudo propietario. Como ejemplo de la última afirmación, Gayo introduce los casos de un servus instituido heredero, o que recibe algo por legado o donación; en estos supuestos -afirma Gayo- la adquisición corresponde al dueño y no al usufructuario ${ }^{19}$.

Idéntico régimen de atribución se aplica cuando un sujeto posee de buena fe un esclavo ajeno o un hombre libre; asílo recoge Gayo en 2,92 [= D. 41,1,10,4 (Gai. 2 inst. ) = Inst. 2,9,4]: "Idem placet ${ }^{20}$ de eo, qui a $a^{21}$ nobis ${ }^{22}$ bona fide possidetur, sive $e^{23}$ liber sit sive alienus servus: quod enim placuit de usufructuario, idem probatur etiam ${ }^{24}$

${ }^{18} \mathrm{La}$ hereditas que se deja a un servus fructuarius no se considera in operis servi: cfr. D. 41,1,47 (Paul., 50 ed.): "Fructuario hereditas adquiri non potest, quod in operis servi hereditas non est".

${ }^{19}$ La cuestión de la adquisición de una herencia, de un legado o de una donación debió ser discutida pues otros textos ofrecen afirmaciones diferentes. Así D.7,1,21 (= FV. 71b) (Ulp., 17 Sab.), con algunos cambios en FV.: "Si servi usus fructus sit legatus, quidquid is ex opera sua adquirit vel ex re fructuarii, ad eum pertinet, sive stipuletur sive ei possessio fuerit tradita. si vero heres institutus sit vel legatum acceperit, Labeo distinguit, cuius gratia vel heres instituitur vel legatum acceperit". La segunda parte del pasaje trae a colación una distinción atribuida -como recuerda Ulpiano- a Labeón en el que el régimen de adquisición -denominémosle, habitual-, se ve alterado en función del sujeto en cuyo favor se hubiera instituido heredero o se recibiera el legado. Aunque no se dice expresamente, por la cuestión planteada, debiera pensarse que se está legando per vindicationem el usufructo sobre un esclavo. Efectivamente si el legado lo hubiera adquirido ya el legatario, ya sería usufructuario y, en consecuencia, el modo de adquirir el legado resultaría irrelevante. En cambio, si pensamos en una situación de espera del legatario per vindicationem, en tanto el heredero decide o no adir la herencia, sí tendría sentido plantearse la adjudicación de esas adquisiciones hechas por el esclavo. Así, en el caso del legado vindicatorio, todo lo que, desde el dies cedens (no sería lo mismo en un legado damnatorio), adquiera ese esclavo ex opera sua o ex re fructuarii, bien mediante una estipulación, bien mediante una traditio, es para el usufructuario. No así, en cambio, cuando el servus fructuarius fuera instituido heredero o recibiera un legado, en cuyo caso, según Labeón, habrá que atender a la intención del testador que instituye o lega. A propósito de las donaciones, también en la primera parte de D. 7,1,22 (Ulp., 18 Sab.), hace se depender la adquisición de la contemplatio del donante: "Sed et si quid donetur servo, in quo usus fructus alterius est, quaeritur, quid fieri oporteat. et in omnibus istis, si quidem contemplatione fructuarii aliquid ei relictum vel donatum est, ipsi adquiret: sin vero proprietarii, proprietario: $s i$ ipsius servi, adquiretur domino, nec distinguimus, unde cognitum eum et cuius merito habuit, qui donavit vel reliquit [...]”. En los supuestos en los que el servus sea instituido heredero, el iussum del usufructuario no es suficiente para cambiar el régimen de adquisición, puesto que el servus usufructuarius no puede adir la herencia aunque medie la autorización de su usufructuario. Cfr. D. 29,2,45,3 (Iul., 1 Urs. Fer.): "Praeterea nec fructuarius quidem servus iussu eius, qui usum fructum in eo habet, adire hereditatem poterit". El iussum para hacer adición de la herencia no aprovecha ni al usufructuario, ni a quien posee de buena fe un esclavo ajeno. Cfr. también D. 29,2,25 pr. (Ulp., 8 Sab.): si quis mihi bona fide serviat servus alienus, iussu meo hereditatem adeundo mihil promovebit nec adquiret mihi, nec fructuarius quidem servus".

${ }^{20}$ Et en Inst.

${ }^{21}$ Omite $a$ D. e Inst.

${ }^{22}$ Vobis en Inst.

${ }^{23}$ Is en Inst.

${ }^{24}$ Placet et en Inst. 
de bonae fidei possessore: itaque quod extra duas istas ${ }^{25}$ causas adquiritur, id vel ad ipsum pertinet, si liber est, vel ad dominum ${ }^{26}$, si servus est".

La consecuencia lógica de observar el mismo régimen es que corresponderán al liber o al dominus las adquisiciones que el liber o el esclavo ajeno, no hiciera con bienes propiedad de quienes los poseen de buena fe.

Una exposición sintética del régimen de adquisiciones al que nos referimos lo encontramos en PS. 5,7,3: "Fructuarius servus si quid ex re fructuarii aut ex operis suis adquirit, ad fructuarium pertinet. quidquid autem aliunde vel ex re proprietarii adquirit, domino proprietatis adquirit".

En este fragmento queda clara la idea de que la adquisición en favor del usufructuario o del nudo propietario se determina por la procedencia de los bienes con los que se hace el negocio ${ }^{27}$.

En cuanto a las adquisiciones del liber o del esclavo ajeno que poseemos de buena fe, aparecen también recogidas en Tit. Ulp. 19,21: "Is, quem bona fide possidemus, sive liber sive alienus servus sit, nobis adquirit ex duabus causis tantum, id est, quod ex re nostra et quod ex operis suis adquirit: extra has autem causas aut sibi adquirit, si liber sit, aut domino, si alienus servus sit. eadem sunt et in eo servo, in quo tantum usumfructum habemus".

Por su parte Gayo y Papiniano nos recuerdan que este régimen de adquisición se aplica igualmente a la possessio.

Gai. 2,94: "De illo quaeritur: an per eum seruum, in quo usumfructum habemus, possidere aliquam rem et usucapere possumus, quia ipsum non possidemus? per eum vero, quem bona fide possidemus, sine dubio et possidere et usucapere possumus. loquimur autem in utriusque persona secundum definitionem, quam proxume exposuimus; id est, si quid ex re nostra uel ex operis suis adquirant, id nobis adquiritur".

D. 41,2,49 pr. (Pap., 2 def.): "Possessio quoque per servum, cuius usus fructus meus est, ex re mea vel ex operis servi adquiritur mihi, cum et naturaliter a fructuario teneatur et plurimum ex iure possessio mutuetur".

$\mathrm{Y}$ asimismo a las obligaciones, a las que el propio Gayo va a referirse en su momento, en el libro tercero, Gai. 3,165 [= Inst. 3,28,2]: Per eum quoque servum, in quo usumfructum habemus ${ }^{28}$, similiter ex duabus istis causis nobi s $^{29}$ adquiritur.

Para aclarar las duae istae causae que menciona Gayo en el fragmento que acabamos de reproducir debemos acudir al pasaje anterior, Gai. 3,164 [= Inst. 3,28,1]: "Per liberos quoque homines et alienos servos, quos bona fide possidemus ${ }^{30}$,

${ }^{25}$ Suprime istas en D.

${ }^{26}$ Dominum eius en D.

${ }^{27}$ En las fuentes aparecen otros bienes con los que el esclavo puede realizar negocios jurídicos -en el caso de las estipulaciones, bienes sobre los que el servus fructuarius puede estipular-; nos referimos a bienes expeculio, aunque, en rigor, estos bienes se reconducen a las categorías de res fructuarii o de res domini dependiendo de quien hubiera concedido el peculio.

${ }^{28}$ Vel usum habetis en Inst.

${ }^{29}$ Vobis en Inst.

${ }^{30}$ Possidetis en Inst. 
adquiritur nobis ${ }^{31}$; sed tantum ex duabus causis, id est, si quid ex operis suis vel ex re nostra ${ }^{32}$ adquirant".

Si en el caso del servus fructuarius la adquisición le corresponde al usufructuario cuando aquélla se hace con res fructuarii o con las operae del esclavo, tratándose, también, de operae de esclavo ajeno o de bienes de quién posee de buena fe, adquiere el sujeto que de buena fe tenga la posesión de un eslavo ajeno o de un hombre libre.

En resumen, se pueden distinguir a la luz de estos textos mencionados, y a título de ejemplo, varios supuestos:

i) Adquisiciones ex re fructuarii (PS. 5,7,3; FV. 71 b), también denominadas, según los textos, como ex re mea (Pap. D. 41,2,49 pr.); ex re nostra (Gai. 2,91= Gai. D. 41,1,10,3; Gai. 2,94; Gai. 3,164; Tit. Ulp. 19,21); o ex re vestra (Inst. $2,9,4$ y $3,28,1)$.

ii) Adquisiciones ex operis suis (Gai. 2,91; Gai. 2,94; Gai. 3, 164 = Inst. 3,28,1; PS. 5,7,3; Tit. Ulp. 19,21; Pap. D. 41,2,49 pr.); ex operibus (Gai. D. 41,1,10,3 = Inst. 2,9,4) o ex opera sua (FV. 71 b).

Estos dos supuestos, Gayo los denomina también como duae causae, ex duabus causis (Gai. 3,164 = Inst. 3,28,1; Tit. Ulp. 19,21), o ex duabus istis causis (Gai. 3,165 = Inst. 3,28,2).

Acerca de este régimen de adquisiciones ex re fructuarii y ex operis, la duda es si sólo se aplica cuando el usufructo se constituye iure legati o, también, cuando se haga mediante traditio, stipulatio o con cualquier otro negocio jurídico. Esta duda se recoge en D. 7,1, 25,7 (Ulp,, 18 Sab.): "Quod autem diximus ex re fructuarii vel ex operis posse adquirere, utrum tunc locum habeat, quotiens iure legati usus fructus sit constitutus, an et si per traditionem vel stipulationem vel alium quemcumque modum, videndum. et vera est Pegasi sententia, quam et Iulianus libro sexto decimo secutus est, omni fructuario adquiri".

Ulpiano resuelve la cuestión siguiendo a Pegaso y a Juliano. Por tanto, el régimen, por otra parte lógico, se aplica a cualquier usufructuario con independencia de cómo se hubiera constituido su derecho.

iii) En consecuencia, cuando no se da alguna de estas duae causae, nos encontraremos ante adquisiciones extra eas causas (Gai. 2,91 = Gai. D. 41,1,10,3 = Inst. 2,9,4); extra duas causas (Gai. D. 41,1,10,4; FV. 71 b); extra duas istas causas (Gai. 2,92 = Inst. 2,9,4); o extra has [...] causas (Tit. Ulp. 19,21); también ex nulla causa (Gai. 3,166, para referirse a "qui nudum ius Quiritium in servo habet", que no puede ex nulla causa adquirir a través del servus).

A su vez, dentro de este tipo de adquisiciones debe distinguirse: $i$ ) adquisiciones ex re domini o ex re proprietarii (PS. 5,7,3); ii) adquisiciones aliunde (PS. 5,7,3).

En el caso de adquisicioners ex re usufructuarii, el servus fructuarius adquiere para el usufructuario; en las restantes (aliunde o ex re propietarii) lo hace para el nudo propietario.

Precisamente este distinto régimen de adquisiciones es el que determina

\footnotetext{
${ }^{31}$ Vobis en Inst.

${ }^{32}$ Vestra en Inst.
} 
contra quien se puede, en su caso, dar la actio de peculio y las demás acciones pretorias. D.15,1,2 (Pomp., 5 Sab.) aplica este régimen general de adquisición al usufructuario y al usuario: "Ex ea causa, ex qua soleret servus fructuarius vel usuarius adquirere, in eum, cuius usus fructus vel usus sit, actio dumtaxat de peculio ceteraeque honorariae dantur, ex reliquis in dominum proprietatis".

Un ejemplo de usufructuario o de aparente dueño demandados con la actio quod iussu nos lo ofrece-D. 15,4,1,8 (Ulp., 29 ed.): "Si iussu fructuarii erit cum servo contractum, item eius cui bona fide servit, Marcellus putat quod iussu dandam in eos actionem: quam sententiam et ego probo".

Recuerda Ulpiano, adhiriéndose al parecer de Marcelo, la legitimación para el ejercicio de la actio quod iussu contra el titular del derecho de usufructo cuando un tercero contrata con un servus fructuarius que actúa con la autorización de su usufructuario.

Un reflejo de cuanto decimos aparece también en la segunda parte de D. 41,1,37 (Iul., 44 dig.): "[...] neque enim ut fructuarius servus ex re fructuarii non adquirit proprietario, ita et communis servus ex re alterius domini non adquirit alteri domino. sed quemadmodum in his, quae aliunde adquiruntur, diversa condicio est fructuarii et servi communis, veluti cum alter fructuario non adquirat, alter dominis adquirat: ita quod ex re quidem fructuarii adquisitum fuerit, ad eum solum pertinebit, quod ex re alterius domini servus communis adquisierit, ad utrumque dominum pertinebit".

Juliano, tras afirmar al comienzo del fragmento que el acreedor pignoraticio no puede adquirir por medio del esclavo entregado para garantizar la relación obligatoria $^{33}$, y de examinar en el siguiente $\$^{34}$ el caso de un copropietario que dona ${ }^{35}$ al servus communis una cantidad de dinero (la adquisición para todos los copropietarios o sólo para el que dona dependerá del propósito con se haga la donación al esclavo ajeno), contrapone en la segunda parte del $\$ 2$, al hilo de lo dicho en la primera parte de este mismo texto ${ }^{36}$, el régimen de adquisiciones del servus fructuarius y del servus communis entre los que hay notables diferencias.

${ }^{33} \$$ pr.: "Per servum, qui pignori datus est, creditori nec possessio adquiritur, quia nec stipulatione nec traditione nec ullo alio modo per eum servum quicquam ei adquiritur, quamvis possessio penes eum sit".

${ }^{34} \$ 1$ : "Si unus ex dominis servo communi pecuniam donavit, in potestate domini est, quemadmodum servo communi pecuniam donet. nam si hoc solum egerit, ut ea separetur a suis rationibus et in peculio servi sit, manebit eiusdem domini proprietas: si vero eo modo pecuniam servo communi donaverit, quomodo alienis servis donare solemus, fiet sociorum communis pro portione, quam in servo habebunt".

${ }^{35}$ Sobre esta don ación, vid. infra $\$ 2$. a).

36 "Sed ut sequens quaestio locum habeat, constituamus socium ita servo communi pecuniam donasse, ut proprietatem suam manere vellet. si ex hac pecunia servus fundum comparaverit, erit is fundus communis sociorum pro portione dominii: nam et si furtivis nummis servus communis fundum comparaverit, sociorum erit pro portione dominii [...]". La frase "pecunia donasse, ut proprietatem suam manere" recuerda la expresión “manebit eiusdem domini proprietas" del \$1, que indica que el copropietario ha don ado la cantidad para que forme parte del peculio del esclavo común y, de ese modo, seguir manteniendo la propiedad. El régimen de adquisición para ambos copropietarios parece el mismo que, a propósito de las adquisiciones en general y también de las estipulaciones del servus communis distinguiéndolo del régimen del servus fructuarius, aparece en D. 45,3,27 
Así, las adquisiciones ex re fructuarii del servus fructuarius no las adquiere el nudo propietario, mientras que las adquisiciones ex re alterius domini del servus communis las adquiere también alteri domini. En los supuestos de adquisiciones aliunde del servus fructuarius, éstas no se adquieren para el usufructuario, en cambio, las del servus communis sí las adquieren ambos dueños. Por último, mientras las adquisiciones del servus fructuarius ex re fructuarii corresponden exclusivamente el usufructuario, las hechas por el servus communis ex re alterius domini pertenecen a ambos copropietarios ${ }^{37}$.

\section{LOS DISTINTOS SUPUESTOS EN LOS TEXTOS}

Así pues, básicamente son tres los posibles supuestos que pueden darse. Sin perjuicio de posteriores referencias, conviene en este punto hacer un breve examen de ellos.

\section{1. "Ex re fructuarii".}

Es evidente que esta expresión se refiere principalmente a los bienes del usufructuario. Sin embargo, la identificación de los bienes cuya naturaleza es ex re fructuarii demuestra que se trata de un concepto más amplio. A estos bienes en general se refiere D. 7,1,31 (Paul., 10 Sab.): "Ex re fructuarii etiam id intellegitur, quod ei fructuarius donaverit concesseritve vel ex administratione rerum eius compendii servus fecerit".

Los bienes mencionados en la primera parte de D. 7,1,31 se reconducen al peculio que el usufructuario dona al servus para que éste lo administre. Las ganancias generadas por su administración, y así aparece en la segunda parte de D. 7,1,31, corresponden también al usufructuario ${ }^{38}$.

Pero llama la atención que Paulo hable de una donatio al esclavo por parte del usufructuario, como si se pudiera hacer una donación en sentido propio a quien es incapaz de ser titular de un patrimonio. Sin embargo, la expresión, aunque puede sorprender, no es inusual, pues son varios los fragmentos en los que aparece mencionada. As D. 41,1,49 (Paul., 9 Plaut.): "Quod fructuarius ex re sua donat, ex re eius est: sed si eo animo id fecerit, ut ad proprietatis dominum pertineat, dicendum est illi adquiri. si autem extraneus ei donet indistincte, soli proprietario adquiritur. eadem dicemus in homine libero, qui bona fide mihi servit, $u$ t, si ei aliquid donave-

(Paul., 2 manual.): "Servus communis sive emat sive stipuletur, quamvis pecunia ex peculio detur, quod alterum ex dominis sequitur, utrique tamen adquirit. diversa causa est fructuarii servi".

${ }^{37} \mathrm{La}$ adquisición del servus communis, a la luz del régimen, aparentemente contradictorio, que ofrecen los textos - valgan a título de ejemplo, los mencionados en la nota anterior-, también ha sido objeto entre la doctrina de un interesante debate en el que, por razones obvias, no vamos a entrar y, por ello, prescindimos de una exhaustiva referencia bibliográfica sobre el tema. No obstante, sobre el texto citado, véase la interpretación que propone BRETONE, Mario "Servus communis". Contributo alla storia della compropietà romana in età classica (Napoli, 1958), p. 19 n. 2 y p. 98 n. 8.

${ }^{38}$ Sobre este punto, véase SALKOWSKI, Zur Lehre vom Sklavenerwerd, pp. 117 ss., citado por Grosso, Giuseppe, Usufrutto e figure affini nel diritto romano (2a edición, Torino ,1958), p. 207. 
rim, meum sit. et ideo Pomponius scribit, quamvis donaverim ei operas suas, tamen quidquid ex operis suis adquiret, mihi adquiri".

Contempla Paulo varios supuestos de donación a un esclavo con sus correspondientes regímenes jurídicos que, sustancialmente, coinciden con los examinados en la primera parte de D. 7,1,22 (Ulp., 18 Sab.) ${ }^{39}$. En primer lugar, la donación del usufructuario ex re sua: lo donado sigue siendo del usufructuario, salvo que hiciera el negocio con la intención de donar al nudo propietario; si la donatio la hace con el propósito de donar al mismo esclavo, entonces adquirirá el nudo propietario. En segundo lugar, la donación de un extraño, sin otra concreción, la adquiere el nudo propietario.

La cuestión es cómo interpretar esa donatio al servus de la que hablan los textos. Tal vez, resulte más preciso no identificar las expresiones donare y concedere con formas de constituir un peculio, sino interpretar el término donatio como sinónimo de la naturalis datio a la que se refiere D. 15,1,8 (Paul., 4 Sab.): "Non statim quod dominus voluit ex re sua peculii esse, peculium fecit, sed si tradidit aut, cum apud eum esset, pro tradito habuit: desiderat enim res naturalem dationem. contra autem simul atque noluit, peculium servi desinit peculium ese".

Frente a la exigencia de esa naturalis datio para constituir un peculio basta, en cambio, la mera voluntad del dueño para que el esclavo deje de tenerlo ${ }^{40}$.

Los textos reproducidos se refieren al peculio como res fructuarii reconducibles al supuesto ex re fructuarii. Pero en el mismo se incluyen, además, otras situaciones en las que el usufructuario, o bien coloca al servus al frente de un negocio marítimo o terrestre, o le autoriza para realizar algún negocio, o simplemente, situaciones en las que, sin más, el servus estipula sobre bienes del usufructuario ${ }^{41}$. Sin duda, en estos supuestos, el esclavo está administrando bienes del usufructuario y, por tanto, a priori, será éste quien adquiera.

2. "Ex operis".

$\mathrm{Al}$ caso se refiere D. 7,7,3 (Gai., 7 ed. prov.): "In hominis usu fructu operae sunt et ob operas mercedes".

Las operae del servus fructuarius entran obviamente dentro del ius utendi fruendi del usufructuario y, en consecuencia, también las mercedes que el esclavo pueda percibir por ellas. Así, por ejemplo, cuando el servus estipula el precio a pagar por el arrendamiento de sus operae, en realidad, lo que hace es estipular ex re fructuarii porque, como decimos, las operae pertenecen al usufructuario, por eso el precio que el servus fructuarius cobra por ese arrendamiento es un fruto civil que le corresponde a aquél ${ }^{42}$.

\footnotetext{
${ }^{39}$ Véase el texto en la n.19.

${ }^{40}$ Sobre la naturalis obligatio del esclavo, véanse, entre otros: Longo, Giovanni, Concetto e limiti dell'obbligazione naturale dello schiavo nel diritto romano, en SDHI., 16 (1950), pp. 86 ss.; BURDESE, Alberto, La nozione classica di naturalis obbligatio (Torino, 1955).

${ }^{41}$ P.ej., cuando estipula de un tercero la constitución de una servidumbre sobre un fundo propiedad del usufructuario.

${ }^{42}$ No se aplica esta adquisición ex operis al servus usuarius según D. 7,8,14 pr. (Ulp., 17 Sab.): "Per servum usuarium si stipuler vel per traditionem accipiam, an adquiram, quaeritur, si
} 
Y puesto que esas operae pertenecen al usufructuario, puede éste obligar al servus fructuarius a trabajar, imponiéndole una modica castigatio, según el parecer de Sabino que se sigue en D. 7,1,23,1 [= FV. 72,1] (Ulp., 17 Sab.) aunque sin excesos, según advierte Casio: "Quoniam autem diximus quod ex operis adquiritur ad fructuarium pertinere, sciendum est etiam cogendum eum operari: etenim modicam quoque castigationem fructuario competere Sabinus respondit et Cassius libro octavo iuris civilis scripsit, ${ }^{43}$ ut neque torqueat, neque flagellis caedat".

En todo caso el usufructuario que, como dicen los textos, tiene derecho a las operae del servus no puede arrendárselas a éste. Así se recuerda en la primera parte de D. 7,1,25,5 (Ulp., 18 Sab.): "Idem Iulianus eodem libro scripsit: si servo fructuarius operas eius locaverit, nihil agit: nam et si ex re mea, inquit, a me stipulatus sit, nibil agit [...]". El usufructuario no puede celebrar un contrato de arrendamiento con el esclavo sobre el que tiene un derecho de usufructo, porque tal arrendamiento es nulo ${ }^{44}$.

\section{3. "Aliunde".}

El sentido de la palabra aliunde quizá no sea unívoco. Hemos visto ya esta expresión en PS. 5,7,3, donde parecen distinguirse tres posibilidades: ex re fructuarii, ex re proprietarii y aliunde, lo que significa que aliunde, contrapuesto a res fructuarii y a res dominii, comprende cualquier tipo de bienes que no pertenecen ni a uno ni a otro.

Y también lo hemos visto en D. 41,1,37,2 (Iul., 44 dig.), donde se contraponen, como ya hemos dicho, las adquisiciones ex re fructuarii del servus fructuarius y las ex re alterius domini del servus communis, a las quae aliunde adquiruntur.

Asimismo, se encuentra también en D. 45,3,18,3 (Pap., 27 quaest.) ${ }^{45}$, donde aliunde se opone a ex re fructuarii vel operis suis, lo que implica que aliunde comprendería ex re domini además de cualquier otra procedencia.

En este mismo sentido, por último, y aunque no se trate de un aliunde original sino de una muy razonable y convincente corrección de Lenel, aparece en D. 45,3,1,5 (Iul., 52 dig.), sobre el que volveremos más adelante ${ }^{46}$, donde frente a la estipulación ex re fructuarii del servus fructuarius, se habla de si aliud stipulatus fuisset, que Lenel corrige por si aliunde stipulatus fuisset ${ }^{47}$.

ex re mea vel ex operis eius. et si quidem ex operis eius, non valebit, quoniam nec locare operas eius possumus: sed si ex re mea, dicimus servum usuarium stipulantem vel per traditionem accipientem mihi adquirere, cum hac opera eius utar". Las diferencias entre el servus fructuarius y el servus usuarius vienen impuestas por el contenido mismo del derecho de uso, pues el usus no da derecho a las operae. En cambio, si el servus usuarius es nombrado institor y empleado en una taberna, sí adquiere para quien tiene el derecho de uso: D. 7,8,20 (Marcell., 13 dig.): "Servus, cuius mihi usus legatus est, adquirit mihi, si institor erit et operis eius utar in taberna: nam mercibus vendundis emendisque adquirit mihi: sed et si iussu meo per traditionem accipiet".

${ }^{43}$ Ita en FV.

${ }^{44}$ Véase infra $\$$ VI.1.

${ }^{45}$ Véase texto y exégesis a propósito del mismo $\$$ VI.3.

${ }^{46}$ Véase infra $\$$ VI.4.

${ }^{47}$ Otros textos en los que aparece aliunde son: D. 47,2,62(61),9 (Afric., 8 quaest.): "Statuliberum, qui, si decem dederit, liber esse iussus erat, heres noxali iudicio defenderat: pendente iudicio 


\section{Dificultades Para APLICAR LOS PRINCIPIOS GENERALES DE ESTAS ADQUISICIONES}

Los principios generales recogidos en las fuentes pueden, en determinadas circunstancias, plantear dificultades para su aplicación, v.gr. cuando no se puede determinar a priori si se trata de una adquisición ex re fructuarii o ex re domini. En estos supuestos, recordados en D. 21,1,43,10 (Pau., 1 ed.cur.)y en D. 41,1,43,2 (Gai., 7 ed. prov.), la adquisición se determinará ex post facto.

D. 21,1,43,10: "Interdum etiamsi pura sit venditio, propter iuris condicionem in suspenso est, veluti si servus, in quo alterius usus fructus, alterius proprietas est, aliquid emerit: nam dum incertum est, ex cuius re pretium solvat, pendet, cui sit adquisitum, et ideo neutri eorum redhibitoria competit".

D. 41,1,43,2: "Cum servus, in quo alterius usus fructus est, hominem emit et ei traditus sit, antequam pretium solvat, in pendenti est, cui proprietatem adquisierit: et cum ex peculio, quod ad fructuarium pertinet, solverit, intellegitur fructuarii homo fuisse: cum vero ex eo peculio, quod proprietarium sequitur, solverit, proprietarii ex post facto fuisse videtur".

El supuesto de hecho en los dos textos es una compraventa realizada por el servus fructuarius de la que todavía no se ha pagado el precio. La adquisición de la mercancía comprada queda pendiente del dinero con el que paga el pretium el servus fructuarius-comprador: si lo hace con dinero del peculio concedido por el nudo propietario, será éste quien adquiera; pero si es con dinero del peculio facilitado por el usufructuario, la mercancía será para él. Y mientras no se resuelva

servus datis decem heredi ad libertatem pervenit: quaeritur, an non aliter absolutio fieri debeat, quam si decem, quae accepisset, heres actori dedisset. referre existimavit, unde ea pecunia data esset, ut, si quidem aliunde quam ex peculio, haec saltem praestet, quoniam quidem si nondum ad libertatem servus pervenisset, noxae deditus ei, cui deditus esset, daturus fuerit: si vero ex peculio, quia nummos heredis dederit, quos utique is passurus eum non fuerit ei dare, contra statuendum", donde se plantea la procedencia de una pecunia que el esclavo había recibido del heredero: "aliunde quam ex peculio [...] ex peculio". Del ejercicio de la condictio indebiti tras el pago a los acreedores y la posterior venta de los bienes de la herencia se ocupa D. 42,5,6,2 (Paul., 58 ed.): "Quid ergo, si quibusdam creditoribus solvit, deinde bona venierint? si quaeritur, an repetitio sit, ex causa id statuendum Iulianus ait, ne alterius aut neglegentia aut cupiditas huic, qui diligens fuit, noceat. quod si utroque instante tibi gratificatus tutor solvit, aequum esse aut prius eandem portionem mihi quaeri aut communicandum quod accepisti: et hoc Iulianus ait. apparet autem loqui eum, si ex bonis paternis solutum sit. quid ergo, si aliunde pupillus solverit? reddi ei debebit nec ne? et utrum a creditore an ex hereditate? Scaevola noster ait, si aliquid sit in bonis, deducendum ex hereditate solidum exemplo eius, qui gessit negotia: sed si nibil sit in bonis, non esse iniquum adversus creditorem dandam repetitionem quasi indebiti soluti". Para el ejercicio de la acción, lo determinante es la procedencia de los bienes con los que paga a los acreedores: "si ex bonis paternis solutum sit. quid ergo, si aliunde pupillus solvit"; por último, D. 41,1,45 (Gai., 7 ed. prov.) = D. 10,3,24 pr. (Iul., 8 dig.) (salvo la frase final en la que aparece precisamente aliunde): "Communis servus si ex re alterius dominorum adquisierit, nihilo minus commune id erit, sed is, ex cuius re adquisitum fuerit, communi dividundo iudicio eam summam praecipere potest: nam fidei bonae convenit, ut unusquisque praecipuum habeat, quod ex re eius servus adquisierit. sed si aliunde servus communis adquisierit, omnibus sociis pro parte dominii hoc adquiritur", en relación con las adquisiciones de un servus communis, distinguiendo "si ex re alterius dominorum adquisierit [...]; sed si aliunde servus communis adquisierit". 
esta alternativa, la eventual acción redhibitoria no le compete a ninguno de los dos como recuerda Paulo en el inciso final de D. 21,1,43,10.

Como veremos más adelante, este régimen es el mismo para ciertas estipulaciones del servus fructuarius ${ }^{48}$.

\section{ESTiPUlaciones dEL “SERVUS FRUCtUARIUS"}

Tras este breve repaso al régimen general de adquisiciones, nos ocuparemos ahora del objeto central de este trabajo, esto es, de las estipulaciones del servus fructuarius.

Conviene comenzar recordando que, como es sabido, en las estipulaciones, se permite la intervención del servus como estipulante, pero no como promitente, pues entonces sólo surgiría una obligación natural. Sirvan como ejemplos de la habitualidad de la estipulación hecha por un servus los siguientes textos: D. 45,3,1 pr. (Iul., 52 dig.): "Cum servus stipuletur, nibil interest sibi an domino an vero sine alterutra eorum adiectione dari stipuletur"; y D. 45,3,15 (Florent., 8 inst.) = Inst. 3,17,1: "Sive mihi sive sibi sive conservo suo sive inpersonaliter dari servi meus stipuletur, mihi adquiret".

El principio general aplicable a las estipulaciones es que adquiere siempre el dominus, con independencia de si el servus ha estipulado para si (sibi), para el dominus (domino), para otro esclavo del mismo dueño (conservo), o sin indicar a favor de quien lo hace (impersonaliter) ${ }^{49}$. En todos los casos, la acción de la estipulación la adquiere siempre el dominus.

Pero este régimen de la estipulación del servus toma unas particularidades especiales cuando se trata de un servus fructuarius. Éste, como decimos, es el objeto central de este trabajo.

Como ya se ha dicho supra a propósito del régimen general de adquisiciones del servus, importa, en primer término, los bienes en relación a los cuales el servus fructuarius estipula. Aquéllos pueden ser ex re domini, ex re fructuarii o aliunde.

Tomemos como punto de partida que nos sirva de paradigma las palabras de D. 45,3,22 (Nerac., 2 resp.): "Servum fructuarium ex re domini inutiliter fructuario stipulari, domino ex re fructuarii utiliter stipular".

Neracio afirma la eficacia de la estipulación del servus fructuarius a favor del nudo propietario con bienes del usufructuario, frente a la ineficacia de una estipulación con bienes del nudo propietario a favor del usufructuario. Como se aprecia en este texto, hay una segunda circunstancia, dadas las características formales de la estipulación, que, de alguna manera, viene a superponerse a la de los bienes. Nos referimos al sujeto a favor de quien el servus fructuarius formula la pregunta estipulatoria. Y aunque en el pasaje sólo aparecen dos de ellas, al menos desde el punto de vista teórico, pueden darse cuatro posibilidades: a favor del dueño

\footnotetext{
${ }^{48}$ Véase más abajo el $\$$ VI. 3.

${ }^{49}$ Sobre si los efectos de la estipulación impersonal eran o no conocidos en el derecho clásico, véase, Scherillo, Gaetano, Sulla stipulazione del servus e del filiusfamilias, en Studi Bonfante (Milano, 1930), IV, pp. 215 ss.
} 
(domino), a favor del usufructuario (fructuario), a favor de sí mismo (sibi) y, por último, a favor de alguien sin determinar (impersonaliter).

En este pasaje de Neracio, explícita o implícitamente, quedan reflejadas cuatro posibilidades derivadas de la combinación de la procedencia de los bienes sobre los que se estipula y de la persona a favor de la cual se estipula. Tales posibilidades son: i) Estipulación ex re domini domino; ii) Estipulación ex re domini fructuario; iii) Estipulación ex re fructuarii domino; y iv) Estipulación ex re fructuarii fructuario. La combinación de estas circunstancias conforma el régimen jurídico de adquisición de la obligación surgida de la estipulación, bien para el usufructuario, bien para el nudo propietario, o bien para ninguno de los dos.

Procedamos a analizar cada uno de los supuestos:

\section{Estipulación "ex re domini" hecha a favor del nudo propietario ("dominus"} o proprietarius").

Este supuesto previsiblemente no suscitaría ningún problema, y el nudo propietario adquiriría sin más la acción de la estipulación. Pero, al menos que hayamos podido localizar, no hay textos referidos a él, quizá por su mismo carácter elemental.

\section{Estipulación "ex re domini" hecha a favor del usufructuario ("fructuario").}

Como acabamos de ver en D. 45,3,22 (Nerat., 2 resp.), esta estipulación es ineficaz (inutilis), y, por tanto, no se genera ninguna obligación a favor del usufructuario.

Pero, a diferencia del supuesto anterior, aquí si cabe encontrar al menos otro pasaje que trata este supuesto, nos referimos a D. 7,1, 25, 3 (Ulp., 18 Sab.): "Quaestionis est, an id quod adquiri fructuario non potest proprietario adquiratur. et Iulianus quidem libro trigensimo quinto digestorum scripsit, quod fructuario adquiri non potest proprietario quaeri. denique scribit eum, qui ex re fructuarii stipuletur nominatim proprietario vel iussu eius, ipsi adquirere. contra autem nibil agit, si non ex re fructuarii nec ex operis suis fructuario stipuletur".

El fragmento está dentro de una secuencia de textos en los que Ulpiano cita a Juliano para solucionar distintos casos que él plantea sobre el sujeto para el que se adquiere: si para el usufructuario o para el nudo propietario. En el fragmento hay dos partes: la primera (quaestionis-quaeri) trata de adquisiciones en general, y en ella se recuerda la opinión de Juliano cuando el usufructuario no pueda adquirir, en cuyo caso, según su parecer, proprietario quaeri. La segunda (denique-fin) trata ya de estipulaciones del servus fructuarius para establecer dos principios: el primero, que el servus fructuarius adquiere para el proprietarius lo estipulado expresamente a favor de éste o con su autorización, aunque la estipulación la haga sobre bienes del usufructuario; el segundo, que es el que ahora nos interesa, aparece en la frase final: "contra autem nibil agit, si non ex re fructuarii nec ex operis suis fructuario stipuletur", e implica que para que la estipulación sea eficaz es necesario hacerla ex re fructuarii (o ex operis); si no es así, lo que sucede cuando el servus fructuarius estipula ex re domini, nihil agit. 
3. Estipulación "ex re fructuarii" hecha a favor del nudo propietario (“dominus").

Como también acabamos de ver en D. 45,3,22 (Nerat., 2 resp.), esta estipulación es eficaz (utilis). Afirmación confirmada por otros testimonios de diferentes juristas. Así D. 41,1,37,5 (Iul., 44 dig.): “Fructuarius servus si dixerit se domino proprietatis per traditionem ${ }^{50}$ accipere, ex re fructuarii totum domino adquiret: nam et sic ${ }^{51}$ stipulando ex re fructuarii domino proprietatis adquireret".

Interesa la frase final del pasaje donde se habla de una estipulación ex re fructuarii, aunque no se mencione explícitamente a favor de quien se ha formulado la pregunta estipulatoria. Pero entendemos que, por una elemental lógica, y por analogía con la primera parte del texto, debe presuponerse que se trata de una estipulación hecha a favor del nudo propietario. En efecto, el hecho de declarar expresamente el servus fructuarius que recibe algo mediante traditio domino proprietatis, lleva a mantener que lo mismo sucede en la estipulación, lo cual vendría manifestado en el et sic stipulando.

El segundo texto que trata de este tipo de estipulaciones pertenece apareece en D. 45,3,39 (Pomp., 22 Q. Muc): "Cum servus, in quo usum fructum habemus, proprietatis domino ex re fructuarii vel ex operis eius nominatim stipuletur, adquiritur domino proprietatis: sed qua actione fructuarius reciperare possit a domino proprietatis, requirendum est. item si servus bona fide nobis serviat et id, quod nobis adquirere poterit, nominatim domino suo stipulatus fuerit, ei adquiret: sed qua actione id reciperare possumus, quaeremus. et non sine ratione est, quod Gaius noster ${ }^{52}$ dixit, condici id in utroque casu posse domino" 53 .

Pomponio aporta dos novedades interesantes. La primera es que el servus fructuarius ha estipulado ex re fructuarii pero expresamente (nominatim) a favor del dominus proprietatis ${ }^{5}$. Esta circunstancia viene a confirmar lo ya dicho en el sentido de que una estipulación hecha ex re fructuarii la adquiere siempre el usufructuario, salvo indicación en contrario expresada en la misma estipulación.

La segunda circunstancia nueva es que Pomponio, dando por hecho que el usufructuario debiera recuperar del nudo propietario lo adquirido por éste ex re fructuarii, se pregunta acerca de la naturaleza de la acción para conseguirlo. Tras acudir a la analogía con el servus bona fide serviens que estipula nominatim domino suo, concluye, invocando la opinión de Gaius noster que en ambos casos, el del

${ }^{50}<$ mancipationem $>$.

${ }^{51}$ si $F$.

${ }^{52}$ Considera interpolado [sed qua actione id - fin] LeneL, 285.

${ }^{53}$ Para las correcciones formales, vid. la literatura recogida por SANTORO, Raimondo, Per la storia della condictio, en Annali Seminario Giuridico Universitá Palermo, 32 (1971), pp. 255 ss. También, en el mismo, una relación de autores que se pronuncian sobre la autenticidad del texto.

${ }^{54}$ SAnfilippo, Cesare, "Odium fructuarii", en Studi Volterra (Milano, 1971), IV, pp. 383-384, hablan de odium fructarii para justficar la peor situación del usufructuario frente al dominus. Hay una serie de decisiones en las que, a su juicio, emerge con claridad un auténtico odium fructuarii y que no encuentran justificación; se trata -añade- de manifestaciones de una arbitrariedad plena y absoluta de la jurisprudencia que ni siquiera pretende justificar. Esta opinión ha encontrado una fuerte contestación por parte de otros autores, quienes critican a Sanfilippo, el acudir a criterios extrajurídicos para justificar ese "agravio sustancial" del que son objeto los usufructuarios. 
servus fructuarius y el del servus bona fide serviens, la acción apropiada para esas reclamaciones será la condictio.

Esta segunda novedad introducida por Pomponio plantea dos cuestiones dudosas. La primera, es la identificación del Gaius noster. La segunda, la naturaleza de la acción concedida al usufructuario para, como dice Grosso, ser indemnizado ${ }^{55}$.

Respecto de la primera cuestión, la opinión mayoritaria se muestra partidaria de no considerar genuina la locución Gaius noster, y entenderla como una interpolación compilatoria ${ }^{56}$. A. d'Ors, recuerda que Gayo fue una figura muy apreciada por Justiniano y a quien los juristas de su época llamaron "nuestro querido maestro" ${ }^{57}$. Sobre quién es el Gaius mencionado en D.45,3,39, Bonfante mantiene que no es otro que Gaio Casio Longino, corifeo de la escuela sabinia$\mathrm{na}^{58}$. En el mismo sentido se pronuncia, entre otros, Santoro ${ }^{59}$, pero sin olvidar a otros autores partidarios de identificarlo con el Gayo de las Institutiones, como es el caso ya citado de A. d'Ors.

Pero sin duda la cuestión de la condictio mencionada por Gayo y Pomponio, es la que mayor extrañeza ha provocado. La solución recogida en D.45,3,39 no deja de suscitar muchas dudas porque, por ejemplo, hablar de la condictio clásica supone una datio previa.

Precisamente la necesidad de esta datio anterior es la que lleva a A. d'Ors a entender que en este texto hay dos acreedores: el acreedor formal sería el nudo propietario, y el usufructuario aparecería como acreedor del negocio causal; pone como ejemplos la venta de una cosa del usufructuario, o el arrendamiento de las operae del esclavo. Entiende A. d'Ors que el promitente ha pagado a su acreedor, de ahí la duda sobre la acción a ejercitar por el usufructuario contra el nudo propietario "para reciperare lo cobrado por éste". A su juicio, el esclavo, al ser el causante de la datio solutionis, adquiere la condictio para el usufructuario ${ }^{60}$.

Pero lo cierto es que el texto no menciona expresamente la datio necesaria para ejercitar la condictio; entrega previa aún más difícil de imaginar si pensamos en una estipulación del servus fructuarius, no ex re fructuarii, sino ex operis eius.

No obstante, no descartemos tajantemente la existencia de una entrega, porque las estipulaciones del servus fructuarius pueden estar ligadas a un negocio sustantivo de cualquier naturaleza que el esclavo hace con bienes fructuarii, pero al que sigue una estipulación en la que el esclavo estipula de un tercero la entrega

${ }^{55}$ Grosso, Giuseppe, cit. (n. 38), p. 225.

${ }^{56}$ Sobre las posibles correcciones del texto se pronuncia KASER, Max, La classicità di Gaio, en Gaio nel suo tempo, en Atti del Simposio Romanistico (Napoli, 1966), p. 44, para quien, aún admitiendo su autenticidad, quedaría la duda de por qué ni Ulpiano, ni Paulo ni ningún otro jurista clásico, lo citaron.

${ }^{57}$ D’Ors, Álvaro, La formación del “ius novum” en la época tardo-clásica, en REHJ. 4 (1979), p. 38.

${ }^{58}$ Bonfante, Pietro, Corso di diritto romano (Milano, 1972), III, pp. 93 ss.

${ }^{59}$ Para un repaso exhaustivo de las posiciones doctrinales sobre este aspecto, véase SANTORO, Raimondo, cit. (n. 53), pp. 255 ss. Él, por su parte, considera (p. 262) que la referencia a Gaio Cassio Longino sirve para mantener que sustancialmente el fragmento se hacía eco de una solución de factura clásica.

${ }^{60}$ D’Ors, Álvaro, Sobre la supuesta condictio sin datio, en Ivra, 25 (1974), pp. 18 ss. 
de algo - por ejemplo, la restitución de lo previamente recibido por el tercero- a favor del nudo propietario. $\mathrm{Y}$ es precisamente lo recibido por el nudo proprietario lo que puede reclamar el usufructuario mediante la condictio.

La ausencia de datio -además de otras razones de carácter formal- llevaron a Donatuti a pronunciarse a favor de la interpolación del texto, aventurando que tal vez Gayo hablara de un remedio pretorio -no dice cuál pudo ser- reagrupado por los compiladores bajo la categoría de la condictio $^{61}$. Así estaríamos ante la genérica condictio postclásica como acción contra el enriquecimiento injusto que puede ejercitarse con independencia de que haya habido o no una datio.

En todo caso, la acción no deja de ser una forma de evitar el detrimento patrimonial sufrido por el usufructuario como consecuencia de la validez de las estipulaciones ex re fructuarii a favor del dominus. En la práctica actuaría como mecanismo corrector de las consecuencias de no utilizar, exclusivamente, la procedencia de los bienes como fundamento del régimen jurídico.

El último texto que examinaremos en este epígrafe es D. 7,1,25,3 que ya hemos reproducido supra ${ }^{62}$. En este tercer fragmento, Ulpiano, citando una opinión de Juliano, repite la misma afirmación: "qui ex re fructuarii stipuletur nominatim proprietario vel iussu eius, ipsi adquirere”. Reaparecer en el mismo la necesidad de que el servus fructuarius formule la estipulación nominatim propietario; requisito que también aparece en el pasaje ya citado de Pomponio ${ }^{63}$.

Pero Ulpiano aporta una nueva variante: que el servus fructuarius hubiera estipulado, no nominatim proprietario, sino iussu eius. En nuestra opinión, no tendría sentido una interpretación cumulativa de ambas modalidades, esto es, el tratase de una estipulación hecha nominatim proprietario iussu eius, pues en tal caso este iussum domini nada aportaría al régimen aplicable. De ahí que parezca más razonable considerarlas como circunstancias disyuntivas: o que la estipulación se haya formulado nominatim proprietario, o que se haya hecho iussu proprietarii, pero sin necesidad de mencionarlo en la pregunta estipulatoria.

4. Estipulación "ex re fructuarii" hecha a favor del usufructuario ("fructuarius").

Se trata del cuarto y último de los supuestos expuestos en D. 4,3,22, y del que se conservan más textos. Veámoslos ${ }^{64}$.

Comenzaremos por D. 7,1,24 (Paul., 10 Sab.): "Si quis donaturus usufruc-

${ }^{61}$ DonatuTi, Guido, Le causae delle condictiones, en Studi di diritto romano (Milano, 1977), II, pp. 803-804, habla de la reiteración de la cuestión planteada por Paulo: "sed quae actione [...] sed qua actione fructuarius reciperare possit", y en la que se hace un cambio en el sujeto fructuarius -nos. Menciona también el error sintáctico de possumus en lugar de possimus.

${ }^{62}$ Véase más arriba el $\$$ IV.2.

${ }^{63} \mathrm{La}$ nominatio, recuerda Grosso, Giuseppe, cit. (n. 38), p. 223, sólo puede actuar en una dirección: a favor del nudo propietario, aunque sea en perjuicio del usufructuario. Recuerda, además (p. 206 n. 1), que en las adquisiciones para el dominus se deja notar el concepto de potestas.

${ }^{64}$ Sobre la estipulación ex re mea del servus usuarius, que es adquirida por el titular del derecho de uso, D. 7,8,14 pr. (Ulp., 17 Sab.): "Per servum usuarium si stipuler vel per traditionem accipiam, an adquiram, quaeritur, si ex re mea vel ex operis eius. et si quidem ex operis eius, non valebit, quoniam nec locare operas eius possumus: sed si ex re mea, dicimus servum usuarium stipulantem vel per traditionem accipientem mihi adquirere, cum hac opera eius utar". 
tuario spoponderit servo in quem usum fructum habet stipulanti, ipsi usufructuario obligabitur, quia ut ei servus talis stipulari possit, usitatum est".

Como afirma Paulo en la parte final del fragmento, usitatum est que el servus fructuarius pueda estipular para el usufructuario (ei). Eso ocurre en el supuesto que el propio Paulo plantea antes: se trata de alguien que quiere hacer una donación al usufructuario de un esclavo, y, a tal fin, promete al servus fructuarius -que interviene como estipulante- el objeto de esa donación, de este modo el donante-promitente queda obligado al usufructuario.

Hay que reconocer que este caso no es estrictamente una estipulación ex re fructuarii, pues lo donado no ha entrado todavía a formar parte del patrimonio del usufructuario-donatario. Quizá por esta razón, parece que la estipulación del servus fructuarius debe hacerse expresamente a favor del usufructuario (ei) al que el promitente quiere hacerle la donación ${ }^{65}$.

Nos ocuparemos ahora de D. 7,1,21 (Ulp., 17 Sab.), texto ya examinado con ocasión del régimen aplicable a las adquisiciones en general ${ }^{66}$ : "Si servi usus fructus sit legatus ${ }^{67}$, quidquid is ex opera sua adquirit vel ex re fructuarii, ad eum pertinet ${ }^{68}$, sive stipuletur sive ei possessio fuerit tradita. si vero heres institutus sit vel legatum acceperit, Labeo distinguit, cuius gratia vel heres instituitur vel legatum acceperit" ${ }^{69}$.

Como dijimos, el texto trata más de las adquisiciones en general que de la estipulación del servus fructuarius ${ }^{70}$. Ulpiano examina un caso en el que se lega per vindicationem el usufructo de un esclavo. El legatario, cuando llegue el momento de adquirir el legado, tendrá derecho a todo lo adquirido ex opera sua o ex re fructuarii $^{71}$, ya el servus lo haya estipulado, ya lo haya recibido por traditio. Pero, al margen de las dificultades suscitadas por la comparación de ambas versiones (D y FV.), lo indiscutible es que la estipulación del servus hecha ex opera sua o ex re fructuarii la adquiere el usufructuario.

Aunque no se habla expresamente de bienes del usufructuario en D. 7,1,23 pr.

${ }^{65}$ De una estipulación donandi causa trata también D. 7,1,25 pr. (Ulp., 18 Sab.): "Sed et si quid stipuletur sibi aut sticho servo fructuario donandi causa, dum vult fructuario praestitum, dicendum, si ei solvatur, fructuario adquiri", pero aquí no es el servus fructuarius quien estipula, sino que es incorporado disyuntivamente como beneficiario de la estipulación: "sibi aut Sticho servo fructuario".

${ }^{66} \mathrm{El}$ argumento, aún con algunos cambios, se recoge en FV. 71b. A pesar de que en los dos textos el régimen sea el mismo, el fragmento vaticano se refiere sólo al contenido del legado cuando se legan los frutos de un esclavo, mientras que en el texto de Ulpiano se habla de legar el usufructo sobre un esclavo para determinar el régimen de adquisiciones. Un estudio detallado del fragmento en CARDilli, Riccardo, La nozione giuridica di fructus (Napoli, 2000), pp.144 ss., y la literatura allí citada.

${ }^{67}$ nunc videndum si [fructus servi legatus sit [...] quid insit in] legato"en FV. 71 b.

${ }^{68}$ [sive manci] pio accipiat ins. en FV. 71 b.

${ }^{69}$ [tradita, quod vero ex re proprietarii, proprie]tario adquirit. et si he[res institutos sit vel legatum acceperit, [...] putat proprietario] quaeri: quamvis Labeo distin[guat, cuius gratia vel heres instituitur vel legatum acceperit] en FV. $71 \mathrm{~b}$.

${ }^{70}$ Véase más arriba el $\$$ I n. 19.

${ }^{71}$ La misma idea, aunque referida con carácter general al legatario del usufructo sobre un esclavo, la encontramos en D. 7,6,5,4a (Ulp., 17 ed.): "[...] quidquid ex re fructuarii vel ex operis suis consecutus est, possessor debebit restituere ". 
(Ulp., 17 Sab.) -que en lo sustancial coincide con FV. 72,1-, sí parece referirse a ellos Ulpiano: "Sed sicuti stipulando ${ }^{72}$ fructuario adquirit, ita etiam paciscendo eum adquirere exceptionem fructuario Iulianus libro trigensimo ${ }^{73}$ digestorum scribit. idemque et si acceptum rogaverit, liberationem ei parere".

Ulpiano, de nuevo citando a Juliano, trata de la estipulación del servus fructuarius. Aunque expresamente nada dice acerca de si aquélla ha sido ex re fructuarii o ex operibus, el régimen aplicado (fructuario adquirit) lleva a pensar que, en efecto, así es.

A continuación, Ulpiano compara la estipulación con el pactum realizado por el mismo servus fructuarius: también en este caso adquiere para el usufructuario: en el primer caso, la acción de la estipulación; en este otro, la exceptio pacti.

Y lo mismo sucede, termina el pasaje, si el servus fructuarius hiciese una acceptilatio, que significaría la liberación del usufructuario-deudor.

De particular interés nos parece este último caso de la acceptilatio, al tratarse de un acto similar, aunque en sentido inverso, a la estipulación. Con la particularidad, además, de que el servus fructuarius que hace aceptilación de una deuda del usufructuario está siempre actuando ex re fructuarii, ya que la cancelación de la deuda implica siempre un incremento patrimonial del usufructuario.

A la acceptilatio del servus fructuarius se refieren también dos textos de Paulo. El primero es D. 46,3,63 (Paul., 9 Plaut.): "Si debitor sit servi fructuarius, potest is servus per acceptilationem liberare eum: videbitur enim ex re eius adquirere. idem in pacto dicemus".

Este fragmento confirma lo que acabamos de comentar: el servus fructuarius que hace aceptilación de una deuda del usufructuario parece adquirir ex re eius. Efectivamente cuando existe una deuda cuyo acreedor es un tercero que nada tiene que ver con el servus fructuarius, y éste realiza con ese tercero acreedor la acceptilatio, el beneficiado es el usufructuario-deudor al estar operando sobre una cosa del usufructuario, por tanto, ex re fructuarii. Es más, va de suyo que esa acceptilatio nunca podrá beneficiar al nudo propietario al no ser éste deudor. Por lo demás, Paulo reitera los mismos argumentos respecto al pacto ${ }^{74}$.

El segundo texto que trata de acceptilatio es D.46,4,11 pr. (Paul., 12 Sab.,): "Species adquirendi est liberare dominum obligatione: et ideo fructuarius quoque servus liberare acceptum rogando fructuarium potest, quia ex re eius videtur ei adquirere.

${ }^{72}$ Stipulatione en FV. 72.1.

${ }^{73} X X X V$ en F.V. 72.1, que parece más acertado sobre la base de D. 2,14,55 (Iul., 35 dig.). Véase la n. siguiente.

${ }^{74}$ Sobre los pactos de petendo o de non petendo celebrados por el servus fructuarius trata D. 2,14,55 (Iul., 35 dig.): "Si debitor sit fructuarius et paciscatur servus, in quo usum fructum habet, ne ab eo petatur: paciscendo meliorem condicionem eius facit. item si creditor esset fructuarius et pactus esset, ne peteret, servus autem fructuarius pacisceretur, ut peteret: beneficio pacti, quod servus interposuisset, utiliter ad petitionem admittetur". El texto resulta muy ilustrativo para aclarar el sentido de D. 7,1,23 pr. En efecto, el texto de Juliano aclara las cuestiones mencionadas a propósito de lo dicho por Ulpiano, aunque sea sólo a propósito del pacto: si debitor sit fructuarius et paciscatur servus, in quo usum fructum habet, nea b eo petatur: [...] item si creditor creditor esset fructuarius et pactus esset, ne peteret, servus autem fructuarius pacisceretur, ut peteret [...]". De aquí se puede deducir que el servus fructuarius está pactando ex re fructuarii. 
sed et si usum tantum habemus, idem fiet. idemque dicemus et in eo, qui bona fide nobis servit, et in ceteris, qui nostro iuri subiecti sunt".

De nuevo encontramos repetida la idea de que liberar al dueño de una obligación es una forma de adquirir y, en consecuencia, el servus fructuarius haciendo una aceptilación puede liberar al usufructuario, puesto que videtur ex re eius ei adquirere. Y lo mismo ocurre, concluye el texto, haciendo una extensión analógica, en los casos del servus usuarius y del bona fide serviens y, en general, con las otras personas que tenemos bajo nuestra potestad.

En síntesis, pues, la estipulación del servus fructuarius hecha ex re fructuarii, la adquiere siempre el usufructuario, salvo que haya estipulado nominatim a favor del nudo propietario o lo haya hecho iussu eius. En cambio, la hecha ex re domini la adquiere siempre el nudo propietario, y si estipula expresamente a favor del usufructuario, la estipulación será inutilis.

\section{V. “Operae”}

Como ya hemos visto antes, se refiere a las operae D.7,1,21 (Ulp., 17 Sab.) ${ }^{75}$ : el legatario-usufructuario adquiere todo lo estipulado por el servus fructuarius, ex opera sua o ex re fructuarii.

Un caso especial de arrendamiento de las operae del servus donde se estipula el pago de una cantidad para cada uno de los años de duración del arrendamiento, lo encontramos en la primera parte de un fragmento de D. 45,3,18,3 (Pap., 27 quaest.), que aquí reproducimos íntegramente ${ }^{76}$ : "Cum servus fructuarius operas suas locasset et eo nomine pecuniam in annos singulos dari stipulatus esset, finito fructu domino residui temporis adquiri stipulationem Iulianus scriptum reliquit. quae sententia mihi videtur firmissima ratione subnixa: nam si in annos forte quinque locatio facta sit, quoniam incertum est, fructus in quem diem duraturus sit, singulorum annorum initio cuiusque anni pecunia fructuario quaereretur: secundum quae non transit ad alterum stipulatio, sed unicuique tantum adquiritur, quantum ratio iuris permittit. nam et cum idem servus ita stipuletur: "quantam pecuniam tibi intra illum diem dedero, tantam dari spondes?" in pendenti est, quis ex stipulatu sit habiturus actionem: si enim ex re fructuarii vel operis suis pecuniam dedero fructuario, si vero aliunde, domino stipulatio quaeretur".

El servus fructuarius, sin indicar a favor de quien, estipula el pago de una cantidad anual por el arrendamiento de sus servicios. Según Papiniano, Juliano habría

\footnotetext{
${ }^{75}$ Véase el texto en la n. 19.

${ }^{76}$ Para comprender el fondo de este texto y del siguiente (D. 7,1,25,2) hay que tener presente los siguientes principios: que el legado in annos singulos se entiende como comprensivo de varios legados sucesivos [D. 33,1,4 (Paul., 62 ed.); D. 33,1,11 (Paul., 21 quaest.); D. 35,2,1,16 (Scaev., 3 quaest.); D. 36,2,10 (Ulp., 23 Sab.), de carácter condicional, porque quedan sometidos sometido a la condición "si vive el legatario" (D. 33,1,4; D. 35,2,1,16); y es equiparable al legado de usufructo en cuanto es intransmisible y se extingue con la muerte [D. 33,1,8 (Gai., 5 leg. Iul. et Pap.); D. 33,1, 22 (Alf., 2 dig.); 45,1,16,1 (Pomp., 6 Sab.)]. En cambio, la estipulación in annos singulos, se entiende como una estipulación única y pura (D. 45,1,16,1). En los textos citados se plantean distintas posibilidades sobre la base de la combinación de los anteriores principios.
} 
escrito que finito fructu domino adquiri, por tanto, mientras dura el usufructo, adquiere el usufructuario; al extinguirse el usufructo, adquiere el nudo propietario.

También D. 7,1,25,2 (Ulp., 18 Sab.) trata del arrendamiento por el servus fructuarius de sus operae: "Si operas suas iste servus locaverit et in annos singulos certum aliquid stipuletur, eorum quidem annorum stipulatio, quibus usus fructus mansit, adquiretur fructuario, sequentium vero stipulatio ad proprietarium transit semel adquisita fructuario, quamvis non soleat stipulatio semel cui quaesita ad alium transire nisi ad heredem vel adrogatorem. proinde si forte usus fructus in annos singulos fuerit legatus et iste servus operas suas locavit et stipulatus est ut supra scriptum est, prout capitis minutione amissus fuerit usus fructus, mox restitutus, ambulabit stipulatio profectaque ad heredem redibit ad fructuarium".

En la primera parte del fragmento el supuesto de hecho y el régimen previsto coinciden sustancialmente con el tratado por Papiniano: el servus fructuarius arrienda operas suas y estipula el pago de una cantidad por cada año, aunque sin mencionar durante cuántos años debe mantenerse el pago del arrendamiento. Al usufructuario le corresponderá la acción de la estipulación en tanto conserve la titularidad del derecho de usufructo. Los años siguientes a la extinción de su derecho, y puesto que la estipulación in annos singulos es trasmisible, la acción pasa al (ya pleno) propietario pese a que -dice Ulpiano- "non soleat stipulatio semel cui quaesita ad alium transire nisi ad heredem vel adrogatorem", de modo que será el (ya pleno) propietario quien pueda ejercitar esa acción mientras dure el arrendamiento.

Los dos últimos textos -en los que hay una obligación ambulatoria-coinciden en admitir el traspaso de la estipulación del usufructuario al nudo propietario, pero manifestando ciertas reservas respecto a la transmisión de la estipulación. Según Juliano-Papiniano, "non transit ad alterum stipulatio, sed unicuique tantum adquiritur, quantum ratio iuris permittit"; Ulpiano, por su parte, escribe: "sequentium vero stipulatio ad proprietarium transit semel adquisita fructuario, quamvis non soleat stipulatio semel cui quaesita ad alium transire nisi ad heredem vel adrogatorem". Incluso parece haber cierta contradicción entre ellos, pero ésta es sólo aparente, porque Ulpiano considera que la obligación estipulatoria nace desde el primer momento, por lo tanto, a favor del usufructuario, de modo que al extinguirse el usufructo se produce la transferencia al dominus. En cambio, Juliano y Papiniano consideran que van naciendo distintas obligaciones anuales y, por ello, no hay transferencia de la obligación, sino que, una vez extinguido el derecho de usufructo, la obligación de ese año nace para el dominus.

En la segunda parte de D. 7,1,25,1, Ulpiano plantea una variante del caso anterior. Hay un legado in annos singulos del derecho de usufructo, y el servus fructuarius arrienda sus operae y estipula ut supra scriptum est (es decir, también in annos singulos) un precio. Pero aquí, para el problema planteado por Ulpiano, no sirve la muerte del usufructuario, pues no permitiría la reaparición del usufructo, y por eso acude a una capitis deminutio. El usufructuario sufre una capitis deminutio y, como consecuencia el usufructo se extingue, pero la acción de la estipulación pasa al (ya pleno) propietario. Ahora bien, si después desaparece la causa de la capitis deminutio, el usufructo reaparece de nuevo (mox restitutus: 
quizá habría que pensar en un postliminium o en una concesión imperial), de este modo la acción estipulatoria vuelve al usufructuario.

La solución prevista por Ulpiano es sustancialmente idéntica en ambos casos aunque en la primera parte del texto, Ulpiano se fije en la duración del derecho de usufructo para establecer el régimen de adquisición, y en la segunda lo haga en la existencia del derecho mismo de usufructo. Como las estipulaciones de este tipo son eficaces, es claro que algún sujeto tiene que estar legitimado para el ejercicio de la acción estipulatoria: si el usufructuario no lo está, aunque se trate de una estipulación ex operis, lo estará el nudo propietario dado el carácter absorbente del derecho de propiedad, como lo denomina Grosso ${ }^{77}$.

\section{Casos especiales}

Nos ocuparemos en este epígrafe de los casos especiales en los cuales el régimen general de adquisición cede en favor de un régimen especial.

1. Caso del "servus fructuarius" que estipula del mismo usufructuario.

Dos textos, uno de Papiniano y otro de Ulpiano, tratan de éste caso.

D. 45,1,118 pr. (Pap., 27 quaest): "Liber homo, qui bona fide servit mibi, quod stipulanti mihi promittit, prope est, ut omnimodo sit utile, quamvis ex re mea promittat: nam quid aliud dici potest, quo minus liber homo teneatur? nec tamen ideo si stipulanti eidem ex eadem causa spondeam, tenebor: quemadmodum etenim habebit eius actionem adversus me, quod ab alio stipulatus quaereret mihi? hoc itaque latere fructuario servo vel alieno, qui bona fide servit, comparabitur. servus autem fructuario si promittat ex re ipsius vel alienus, qui bona fide servit, emptori, nulla de peculio dabitur in dominum actio: nam in his causis domini esse intelleguntur".

La referencia al servus fructuarius estipulante es indirecta, y traída a colación a propósito del liber homo bona fide serviens: cuando el aparente dueño estipula ex re mea y promete el liber bona fide serviens, la estipulación es eficaz; cuando, en cambio, es el liber bona fide serviens quien estipula ex eadem causa del aparente dueño, entonces la estipulación no es eficaz, pues -justifica Papiniano- "quemadmodum etenim habebit eius actionem adversus me, quod ab alio stipulatus quaereret mihi?", es decir, no cabe acción contra quien ha prometido a quien, de haber estipulado de otro, hubiese adquirido para él.

Y este segundo supuesto (hoc itaque latere), Papiniano lo compara con los casos del servus fructuarius y del servus alienus bona fide serviens, estipulantes respectivamente del usufructuario o del aparente dueño: la estipulación será ineficaz y, por tanto, el usufructuario no tiene la acción de peculio contra el nudo propietario.

De D. 7,1,25,5 (Ulp., 18 Sab.) nos hemos ocupado en el epígrafe dedicado a las adquisiciones en general: "Idem Iulianus eodem libro scripsit: si servo fructuarius operas eius locaverit, nihil agit: nam et si ex re mea, inquit, a me stipulatus sit, nibil agit, non magis quam servus alienus bona fide mihi serviens idem agendo domino quicquam adquirit. simili modo, ait, ne quidem si rem meam a me fructuario con-

${ }^{77}$ Grosso, Giuseppe, cit. (n. 38), p. 223. 
ducat, me non obligabit. et regulariter definiit: quod quis ab alio stipulando mihi adquirit, id a me stipulando nihil agit: nisi forte, inquit, nominatim domino suo stipuletur a me vel conducat".

La peculiaridad de este caso está en tratarse de una estipulación ex re fructuarii en la que se estipula precisamente del usufructuario: esta estipulación resulta nula (nibil agit), salvo que nominatim domino suo stipuletur a me en cuyo caso, adquiere el nudo propietario. En este sentido Ulpiano enuncia una regla general: "quod quis ab alio stipulando mihi adquirit, id a me stipulando nibil agit".

2. El caso del "servus fructuarius" que estipula por una causa distinta de aquellas por las que suele adquirir el usufructuario, o estipula algo que no puede adquirir el usufructuario.

Del supuesto se ocupa D. 45,3,31 (Paul., 8 Plaut.): "Si iussu fructuarii aut bonae fidei possessoris servus stipuletur, ex quibus causis non solet iis adquiri, domino adquirit. non idem dicetur, si nomen ipsorum in stipulatione positum sit".

El servus fructuarius, iussu fructuarii, estipula, pero porque se trata de alguno de los casos en los que no suele adquirir el usufructuario, domino adquirit.

Hemos de preguntarnos por el sentido de ese ex quibus causis non solet iis adquiri mencionado por Paulo. Parece lógico identificar estas causae con las que, como veíamos al comienzo, justificaban o no la adquisición por el usufructuario. Decíamos entonces que adquiría el usufructuario cuando fueran adquisiciones ex re fructuarii o ex operis servi; las demás (ex re domini o aliunde) serían extra eas causas, y a ellas se referiría el fragmento. Según esto, lo que Paulo viene a afirmar es que, cuando no se trate de adquisiciones ex re fructuarii o ex operis, el iussum del usufructuario es irrelevante y no determina la adquisición por su parte de la obligación nacida de la estipulación, que sí es adquirida por el nudo propietario.

Todo esto es así salvo que al formular la pregunta estipulatoria se haya incluido expresamente el nombre del usufructuario, en cuyo caso entendemos, pues el texto no lo dice expresamente, que la estipulación es ineficaz, por tanto, el nudo propietario no puede adquirir.

De otro usufructuario que no puede adquirir trata D. 7,1,25,4 (Ulp., 18 Sab.): "Servus fructuarius si usum fructum in se dari stipuletur aut sine nomine aut nominatim proprietario, ipsi adquirit exemplo servi communis, qui stipulando rem alteri ex dominis cuius res est, nihil agit, quoniam rem suam stipulando quis nibil agit, alteri stipulando adquirit solidum".

Es claro que el servus fructuarius estipula; el objeto de esa estipulación es que se de el derecho de usufructo sobre sí mismo. Además, el servus estipula sin mencionar a favor de quien (sine nomine), o lo hace expresamente a favor del nudo propietario (nominatim proprietario): en ambos casos se adquiere para el propietario.

Como en el texto no se especifica quién es el promitente de esa estipulación cabría conjeturar que, siendo el objeto de la estipulación el derecho de usufructo precisamente sobre el estipulante del que es titular el usufructuario, fuese éste quien prometiera.

Sin embargo, si acudimos a la analogía con el servus communis el fragmento nos sugiere otra idea. Se plantea en la segunda parte del fragmento la estipulación del 
servus communis para uno de los condueños propietario de la cosa estipulada. Esta estipulación es nula, porque no se puede estipular una cosa propia. En cambio, si estipula para el otro condueño, éste adquiere la cosa entera. Si aplicamos esta solución al caso del servus fructuarius, nos encontraríamos con una estipulación en la que el servus estipula el derecho de usufructo sobre sí mismo. Y si esa estipulación la hace sine nomine o nominatim proprietario, entonces adquiere para éste. En cambio, si estipula a favor del usufructuario, como éste ya tiene el derecho de usufructo, la estipulación forzosamente resultará nula.

A la luz de los textos examinados, queda de manifiesto la imposibilidad de adquirir para el usufructuario, aún tratándose de bienes suyos, porque razones de naturaleza varia le impiden ejercitar la actio ex stipulatu. Y aunque no se encuentren textos que lo confirmen expresamente, cabe también conjeturar, por analogía con el caso del servus communis, que el usufructuario no puede adquirir, no sólo cuando se estipula una cosa que ya le pertenece, sino también, por ejemplo, cuando el esclavo estipula una servidumbre sobre un fundo del usufructuario que no puede ser dominante ${ }^{78}$ o una dote, cuando el usufructuario no vaya a casarse ${ }^{79}$.

3. Supuestos en los que si trata de adquisición "ex re domini" o "ex re fructuarii" se determina "ex post facto".

En los casos precedentemente examinados, al estipular se sabe si es ex re domini o ex re fructuarii. Pero en el presente caso, eso solo se conoce ex post facto.

Considérese D. 7,1,25,1 (Ulp., 18 Sab.): "Interdum tamen in pendenti est, cui adquirat iste fructuarius servus: ut puta si servum emit et per traditionem accepit necdum pretium numeravit, sed tantummodo pro eo fecit satis, interim cuius sit, quaeritur. et Iulianus libro trigensimo quinto digestorum scripsit in pendenti esse dominium eius et numerationem pretii declaraturam, cuius sit: nam si ex re fructuarii, retro fructuarii fuisse. idemque est et si forte stipulatus sit servus numeraturus pecuniam: nam numeratio declarabit, cui sit adquisita stipulatio. ergo ostendimus in pendenti esse dominium, donec pretium numeretur. quid ergo si amisso usu fructu tunc pretium numeretur? Iulianus quidem libro trigensimo quinto digestorum scripsit adhuc interesse, unde sit pretium numeratum: Marcellus vero et Mauricianus amisso usu fructu iam putant dominium adquisitum proprietatis domino: sed Iuliani sententia humanior est. quod si ex re utriusque pretium fuerit solutum, ad utrumque dominium pertinere Iulianus scripsit, scilicet pro rata pretii soluti. quid tamen si forte simul solverit ex re utriusque, ut puta decem milia pretii nomine debebat et dena solvit ex re singulorum: cui magis servus adquirat? si numeratione solvit ${ }^{80}$, intererit,

${ }^{78}$ Cfr. D. 45,3,17 (Pomp., 9 Sab.): "Si communis servus meus et tuus viam vel iter vel actum stipuletur sine adiectione nominis nostri, cum ego solus fundum vicinum habeam, soli mihi eam adquirit: quod et si tu fundum habeas, mihi quoque in solidum servitus adquiritur. D.45,3,7,1 i. f. Ulp. 48 Sab.: [...] interdum etiamsi neque iussu neque nominatim alteri ex dominis stipularetur, ei tamen soli adquirere eum Iuliano placuit: ut puta si quid forte stipuletur, quod utrique adquiri non potest. veluti servitutem ad fundum Cornelianum stipulatus est, qui fundus Sempronii erat alterius ex dominis: ei soli adquirit".

${ }^{79}$ Cfr. D.45,3,8 (Gai., de casib.): "Item si alter ex dominis uxorem ducturus sit et huic servo dos promittatur".

${ }^{80}$ solvat $F^{2}$. 
cuius priores nummos ${ }^{81}$ solvat: nam quos postea solverit, aut vindicabit ${ }^{82}$ aut, si fuerint nummi consumpti, ad condictionem pertinent: si vero simul in sacculo solvit, nihil fecit accipientis et ideo nondum adquisisse cuiquam dominium videtur, quia cum plus pretium solvit servus, non faciet nummos accipientis".

En este fragmento que examina la controversia de para quién se adquiere, trata Ulpiano del servus fructuarius comprador de un esclavo: la cuestión a resolver es quién adquiere el dominio. Aunque se habla de estipulación hecha por el servus fructuarius, conviene analizar el contenido del texto para facilitar la explicación propuesta, precisamente, para el caso de estipulación. Como decimos, el supuesto de hecho es la compra por el servus fructuarius de un esclavo del que todavía no se ha pagado el precio: "in pendenti esse dominium donec pretium numeretur". El hecho de no haber pagado aún le suscita a Ulpiano la duda de a quién corresponderá la propiedad de lo adquirido. Juliano (35 dig.) resuelve la cuestión atribuyendo la titularidad al dueño del dinero con el que se paga el precio, de modo que "nam si ex re fructuarii, retro fructuarii fuisse" ${ }^{\text {"3 }}$. El mismo Juliano mantiene el criterio de la procedencia del dinero incluso cuando el usufructo se hubiera extinguido. Esta opinión no es compartida por Marcelo y Mauriciano: "usu fructu iam putant dominium adquisitum proprietatis domino" ${ }^{84}$. Cuando el precio se paga con bienes parte del usufructuario y parte del nudo propietario, el dominio pertenece a ambos en proporción a la parte del precio pagado por cada uno, pero cuando se paga simultáneamente con dinero del usufructuario y del nudo propietario, se adjudicará la propiedad a aquél al que pertenezcan las primeras monedas entregadas como precio; el resto pueden ser reivindicadas, o si las monedas fuerint consumpti, se reclamarán con la condictio ${ }^{85}$. La última variante de este régimen general de atribución dominical surge cuando las monedas del usufructuario y del nudo propietario se entregan mezcladas en una talega -in sacculo-: como el servus fructuarius pagó de más, queda pendiente determinar a quién corresponde el esclavo comprado. En este caso, se entiende que tras la restitución del dinero

${ }^{81}$ ummos $F$.

82 vindicabuntur $M o$.

${ }^{83}$ Entiende DonatuTti, Guido, cit. (n. 61), p. 742, que el dinero con el que paga el esclavo procede del peculio concedido por el usufructuario o por el propietario, de modo que adquirirá para sí, el dueño del peculio del que proceda el dinero con el que se realice el pago de la compra venta. Aunque es posible que el propietario o el usufructuario hubieran concedido un peculio al esclavo, y que éste pagara con dinero procedente de alguno de ellos, la solución es la misma si el servus fructuarius paga administrando bienes ex re fructuarii o ex re domini aunque no procedieran, necesariamente, de un peculio.

${ }^{84}$ A juicio de Ulpiano, la opinión de Juliano es más humana. Algún autor ha cuestionado esta afirmación, pero tampoco resulta tan extraña al estar en sintonía con la mantenida por el mismo Juliano acerca de la conservación del derecho de usufructo sobre un servus fructuarius fugitivus poseído o no por un tercero. Véase, más abajo el $\$$ VI,6.

${ }^{85} \mathrm{La}$ libre administración del peculio, presupuesto del que parte DonATUTTI, Guido, cit. (n. 61), p. 742, no comprende el pago de lo indebido por parte del servus, de ahí que pueda ejercitarse la condictio indebiti desde el momento en que el segundo pago, hecho con dinero del otro peculio, no convierte en propietario al accipiens. 
pagado, la procedencia de las monedas para hacer el nuevo pago, determinará la titularidad del esclavo ${ }^{86}$.

Este régimen se completa con un servus fructuarius comprador en el puesto de estipulante. Esta estipulación es la cuestión que interesa en este momento. De ella, el texto no dice ni lo que estipula, ni a favor de quién lo hace.

El objeto de la estipulación, no puede ser el precio de la compra venta porque el servus fructuarius comprador es el obligado a pagarlo. Pero, sin mencionar a favor de quién, sí puede estipular del vendedor la evicción o la garantía por los vicios redhibitorios, en cuyo caso, coherentemente con el régimen general, numeratio declarabit, cui sit adquisita stipulatio, por tanto, mientras no se pague el precio y se sepa quien es el propietario del esclavo comprado, tampoco se sabrá quién adquiere las mencionadas estipulaciones ${ }^{87}$.

También se determina ex post facto el tipo de estipulación en D. 45,3,18,3 (Pap., 27 quaest.): "Cum servus fructuarius operas suas locasset et eo nomine pecuniam in annos singulos dari stipulatus esset, finito fructu domino residui temporis adquiri stipulationem Iulianus scriptum reliquit. quae sententia mihi videtur firmissima ratione subnixa: nam si in annos forte quinque locatio facta sit, quoniam incertum est, fructus in quem diem duraturus sit, singulorum annorum initio cuiusque anni pecunia fructuario quaereretur: secundum quae non transit ad alterum stipulatio, sed unicuique tantum adquiritur, quantum ratio iuris permittit. nam et cum idem servus ita stipuletur: "quantam pecuniam tibi intra illum diem dedero, tantam dari spondes?" in pendenti est, quis ex stipulatu sit habiturus actionem: si enim ex re fructuarii vel operis suis pecuniam dedero, fructuario, si vero aliunde, domino stipulatio quaeretur".

Interesa la parte final del texto donde Papiniano trata de una estipulación del servus fructuarius hecha en los términos siguientes: "quantam pecuniam tibi intra illum diem dedero, tantam dari spondes?", preguntándose quién dispondrá de la acción de la estipulación. In pendenti est, responde: si el dinero ha sido dado "ex re fructuarii vel operis suis", la acción la tendrá el usufructuario; pero si aliunde, entonces, el nudo propietario.

4. Caso en que el "servus fructuarius" puede estipular a favor alternativamente del usufructuario o del nudo propietario.

Tal caso aparece examainado en D. 45,3,1,5 (Iul., 52 dig.): "Si fructuarius servus stipulatus esset fructuario aut proprietario, si quidem ex re fructuarii stipulatus esset, inutilis est stipulatio, quia utrique ex re fructuarii actionem adquirere potuisset: sed si aliud ${ }^{88}$ stipulatus fuisset, proprietarium petere posse, et, si promissor fructuario solvisset, liberatur" 89 .

${ }^{86}$ Para otros supuestos dudosos en los que Juliano aplica la teoría de la pendencia del dominio, Bonfante, Pietro, cit. (n. 58), p. 93.

${ }^{87}$ Sobre el texto, véase: BucKLAnd, William, The Roman Law of Slavery: The Condition of the Slave in Private Law from Augustus to Justinian (Cambridge, 1908), pp. 364 ss. También, EsPINOSA, Thea, En torno a la "stipulatio" y las adquisiciones "in pendenti" por parte del "servus fructuarius”, en SDHI., 54 (1988), pp. 269 ss.

${ }^{88}$ Aliunde, LENEL.

${ }^{89}$ Sed-fin lo suprime CugIA, Stanislao, L"”adiectus solutionis causa" (Napoli, 1919), p. 84. 
Si el servus fructuarius estipula alternativamente para el usufructuario o para el nudo propietario se distinguen dos supuestos: que sea ex re fructuarii, en cuyo caso la estipulación es ineficaz (inutilis) porque cualquiera de los dos adquiere la acción de la estipulación, algo que no puede admitirse por la incertidumbre que suscita $^{90}$. En cambio cuando la estipulación se hace con bienes de otra procedencia, aliunde, la acción nace para el nudo propietario, y si el promitente paga al usufructuario, queda liberado, lo que supone reconocer la condición de adiectus solutionis gratia al usufructuario.

Los mismos supuestos anteriores, con también las mismas soluciones, se repiten en la segunda parte de D. 46,3,98,7 (Paul., 15 quaest.): "Si servus fructuarius ex re fructuarii domino proprietatis aut fructuario stipuletur ${ }^{1}$, inutilis est stipulatio: at ex re proprietarii si ipsi domino aut fructuario stipuletur, recte stipulatur: tantum enim solutionis capax est fructuarius hoc casu, non etiam obligationis"92.

Aunque el último inciso ha sido cuestionado ${ }^{93}$, la única diferencia con el texto de Ulpiano está en que donde éste habla de aliunde (según la corrección de Lenel), Paulo lo hace de ex re proprietarii. Por lo demás, nada se dice del por qué de la inutilidad de la estipulación ex re fructuarii hecha alternativamente.

De nuevo encontramos idéntico régimen en D. 45,3,28 pr. (Gai., 3 verb. oblig.): "Si ex re domini domino aut fructuario servus stipulatus fuerit, domino quidem adquiri obligationem Iulianus scripsit, solvi autem fructuario posse, quasi quolibet adiecto".

Gayo recuerda el parecer de Juliano: la estipulación alternativa ex re domini legitima al dominus para el ejercicio de la actio ex stipulatu: el usufructuario está legitimado para recibir el pago, pero no para reclamarlo.

En el régimen previsto para las estipulaciones alternativas ex re domini, queda claro el propósito de los juristas romanos por salvar su validez. Sin embargo, podríamos cuestionarnos por qué -a diferencia de otros supuestos- no se aplicó el mismo criterio previsto para el servus communis, es decir, por qué no se consideró ineficaz la estipulación referida al usufructuario. La razón pudiera ser que el usufructuario, quien de ningún modo puede adquirir en estos casos, sí estaría legitimado para recibir el pago.

5. Estipulaciones del siervo en usufrcuto de varios.

a) Como recuerda Kuntze, no debió ser una situación excepcional la concu-

Véase Index Interp. ad legem.

${ }^{90} \mathrm{El}$ criterio es el mismo que el previsto para las estipulaciones alternativas hechas por el servus communis, cfr. D. 45,3,21 (Ven.,1 stip.): "Si servus communis ita stipuletur: 'kalendis Ianuariis decem Titio aut Maevio dominis, uter eorum tunc vivet, dare spondes?, inutilem esse stipulationem Iulianus scribit, quia non possit [quia possit non Mo.] in pendenti esse stipulatio nec apparere, utri eorum sit adquisitum. D. 45,3,10 (Iul., 52 dig.): "sed si ita stipuletur: 'Titio decem aut Maevio fundum dare spondes?", quia incertum est, utri forum adquisierit actionem, ideirco inutilis stipulatio existimanda est".

${ }^{91}$ Stipuleretur (sic) F.

${ }^{92}$ Quoque (quoque del. $F^{2}$ ) erant ins. F.

${ }^{93}$ Véase. Index. interp. ad legem. 
rrencia de varios derechos de usufructo sobre un mismo esclavo ${ }^{94}$. El régimen jurídico de las estipulaciones hechas por un servus co-usufructuarius trata de resolver la legitimación para el ejercicio de la actio ex stipulatu.

A priori, el régimen, como en los casos ya examinados, se determina, en primer lugar, por la procedencia de los bienes sobre los que estipula el esclavo $y$, subsidiariamente, por la persona a favor de quien lo hace. A esto se añade que, en el co-usufructo, la adquisición entre co-usufructuarios es por cuotas de participación en el derecho.

Aplicadas estas premisas al co-usufructo suponen la adquisición para los cousufructuarios cuando el servus estipule a favor de ellos ex re fructuarii sobre bienes comunes a los dos. La adquisición se limita al usufructuario propietario cuando se estipule con bienes de su propiedad.

Pero los textos no siempre reflejan este régimen, porque aparecen circunstancias distorsionadoras del régimen general; así se puede estipular sobre bienes de uno de los usufructuarios, pero a favor de quien no es titular de esos bienes, $y$ entonces ¿quién adquirirá la parte que el usufructuario no propietario no puede adquirir por no ser bienes ex re fructuarii suyos?

La situación se complica aún más cuando se estipula con autorización o a favor expresamente de uno de los usufructuarios sobre bienes del otro usufructuario. La concurrencia de estas circunstancias, aparentemente, suponen un cambio de régimen.

Examinaremos primero los textos en los que el régimen de adquisición se determina exclusivamente por la procedencia de los bienes.

No plantea ninguna controversia que un servus, sobre bienes de uno de los cousufructuarios, estipule sin mencionar a alguien concreto, o a favor del dueño de esos bienes. Este es el caso del que parece tratar D.45,3,27 (Paul., 2 man.): "Servus communis sive emat sive stipuletur, quamvis pecunia ex peculio detur, quod alterum ex dominis sequitur, utrique tamen adquirit $t^{95}$. diversa causa est fructuarii servi".

El asunto central tratado por Paulo es el de un servus communis que estipula con bienes del peculio concedido por uno de los dueños, en cuyo caso, utique adquirit ${ }^{96}$. Sin embargo, diversa causa est-dice Paulo-cuando se trata de un servus fructuarius. Si atendemos a la contraposición planteada por Paulo no parece razonable suponer que se estuviera refiriendo al nudo propietario y a un único usufructuario, porque de ser así, si aplicamos el régimen general, adquiriría el nudo propietario cuando el esclavo comprara o estipulara con bienes del peculio concedido por él al servus. En cambio, si la compra o la estipulación la hace el

\footnotetext{
${ }^{94}$ Habitualidad que recuerda KunTZE, Johannes E., Der "servus fructuarius" des römischen Rechts (Leipzig, 1889), pp. 55 ss.

${ }^{95}$ Véase la decisión contraria cuando el servus communis presta dinero del peculio de uno de los copropietarios. Supuesto que recoge D. 45,3,1,2 (Iul., 52 dig.): "Si servus communis meus et tuus expeculio, quod ad te solum pertinebat, mutuam pecuniam dederit, obligationem tibi adquiret [...]".

${ }^{96}$ Sobre el reparto posterior, D.45,3,28,1 (Gai., 3 verb.oblig.): "Si servus communis ex re unius stipulatus erit, magis placuit utrique adquiri, sed eum, cuius ex re facta est stipulatio, cum socio communi dividundo aut societatis iudicium de parte reciperanda recte acturum: idemque esse dicendum et si ex operis suis alteri ex dominis servus adquirit".
} 
servus fructuarius sobre bienes concedidos como peculio por el usufructuario, el legitimado para el ejercicio de la correspondiente acción sería el usufructuario. En el primer caso se trataría de una adquisición ex re dominii, y en el segundo de una adquisición ex re fructuarii.

Precisamente porque este régimen no plantea ninguna controversia, parece más acertado referir las palabras de Paulo a un usufructuario sobre el que recaen varios derechos de usufructo. $\mathrm{Y}$ en tanto la solución es distinta a la del servus communis, adquirirá sólo el dueño del peculio y no ambos.

Pensemos ahora en un servus fructuarius que estipula ex operis para uno de los co-usufructuarios. El objeto de esta estipulación es el pago del precio por las operae del esclavo, exigible al promitente. Si la cantidad debida como precio se consideran bienes comunes, ¿quién, y por cuánto, podrá reclamar cada usufructuario?

En D.45,3,24 (Nerat., 2 resp. ) se expresa la siuguiente opinión: "Et si duorum usus fructus sit, quod ex operis suis alteri eorum stipulatus sit, pro ea dumtaxat parte, ex qua usus fructus eius sit, adquiri". Legitimado estará el usufructuario a favor de quien hubiera estipulado el esclavo en proporción a su cuota de usufructo.

¿Qué impide al usufructuario mencionado adquirir íntegramente? Un breve recordatorio de los textos que tratan del régimen de atribución, nos ofrece la solución: la adquisición en el derecho de usufructo se hace por cuotas. Y en el caso que nos ocupa, aplicarlo no ofrece mayores dificultades porque el precio por las operae es una obligación de dare divisible.

El texto no va más allá sobre el destino de la parte no adquirida por el usufructuario a cuyo favor se estipula. Ante el silencio, inevitablemente hemos de movernos en el terreno de las conjeturas y en él, tal vez no resulte extraño aventurar que Neracio no tuviera en mente pronunciarse sobre el destino de la parte no adquirida, sino que se limitó a recordar el régimen de adquisición por cuotas.

En el mismo terreno de las conjeturas, porque, como decimos, el texto no aporta otra solución, cabe, por analogía con las palabras de Juliano recogidas en D. 7,1,25,3, la adquisición para el nudo propietario dado que el usufructuario mencionado en la pregunta estipulatoria no puede adquirir íntegramente. La adquisición para el nudo propietario encontraría su justificación en la naturaleza absorbente de la propiedad frente al usufructo. Sin embargo esta solución presenta el inconveniente, por lo menos a priori, de privar al otro usufructuario de la cuota de operae que le corresponde ${ }^{97}$. De nuevo nos vemos obligados a conjeturar: si Neracio no cuestiona el régimen general de adquisición en el usufructo, tampoco tiene necesidad de recordar los mecanismos procesales con los que el otro usufructuario reclamaría su parte del precio, sino que, como hemos dicho, se habría limitado a recordar la adquisición por cuotas.

El régimen de atribución por cuotas se resuelve fácilmente cuando nos encontramos ante obligaciones divisibles. Mayores dificultades suscitan las obligaciones

\footnotetext{
${ }^{97}$ Decimos a priori, porque en otros pasajes se contempla posibilidad de que el usufructuario reclame del nudo propietario lo que éste hubiera adquirido ex operis. Con todo, estipular un precio por las operae, aunque no aparezca mencionado uno de los usufructuarios en la estipulación, no es una circunstancia por la que no pueda adquirir en ningún caso, supuesto al que parece que se refiere D. 7,1,25,3.
} 
indivisibles, y la situación se complica aún más cuando la estipulación indivisible se hace sobre bienes del otro usufructuario.

b) La procedencia de los bienes determina el régimen general de adquisición, aunque determinadas circunstancias, como son el iussum y la nominatio, pueden alterarlo. Veamos algunos textos que se ocupan de las consecuencias jurídicas de estas circunstancias. Analicemos, en primer lugar, D. 45,3,33,1 (Paul., 14 Plaut.): "Si duo rei stipulandi usum fructum in servo habeant vel quibus ${ }^{98}$ bona fide serviebat et iussu unius a debitore stipuletur, ei soli adquirit". Su lectura produce cierta extrañeza.

Trata Paulo de la pregunta simultánea formulada por dos acreedores solidarios al deudor; de ella surge una única relación obligatoria entre los acreedores estipulantes y el deudor promitente. Existiendo ya esta obligación, el esclavo, con autorización de uno de los co-usufructuarios - iussu unius-, estipula del deudor de los acreedores solidarios. Aunque Paulo no dice nada sobre la procedencia de los bienes con los que estipula el servus, ni tampoco especifica a favor de cuál de los co-usufructuarios lo hace. Curiosamente las dos cuestiones no mencionadas son la clave de por qué Paulo entiende que se adquiere para el autorizante.

Claro que para una mejor compresión de este régimen, conviene detenerse en el objeto de la estipulación. Cuando el servus estipula con la autorización de uno de los usufructuarios, sólo puede surgir una estipulación novatoria porque existe una única obligación que, aplicando la teoría de las obligaciones solidarias, cualquiera de los acreedores-usufructuarios puede extinguir sin que el otro usufructuario resulte perjudicado. Pensar que el esclavo estipula algo distinto a lo ya estipulado por los usufructuarios, resta valor al hecho de ser acreedores solidarios pues se trataría de una obligación nueva sin relación alguna con lo estipulado en un primer momento por los co-usufructuarios ${ }^{99}$.

Resuelto el objeto de la obligación, ¿sobre qué bienes se estipula? Si los bienes son del usufructuario que autoriza, éste adquirirá. Este supuesto no plantea ninguna duda. En cambio, si se trata de bienes del otro usufructuario, es posible que no sea éste quien adquiera, y en su lugar lo haga el usufructuario (no propietario) autorizante de la estipulación, cambiando así el régimen general de adquisición. ¿Quiere eso decir que el iussum justifica un enriquecimiento injusto? Hasta donde llegan las palabras de Paulo, la respuesta, de momento, tiene que ser afirmativa.

c) Si el iussum modifica el régimen de adquisiciones, a la nominatio se le reconocen idénticas consecuencias ${ }^{100}$, incluso tratándose de bienes comunes a los usufructuarios.

De este caso trata D. 45,3,32 (Paul., 9 Plaut.): "Si, cum duorum usus fructus esset in servo, et ${ }^{101}$ is servus uni nominatim stipulatus sit ex ea re, quae ad utrosque

${ }^{98}$ quibus] duobus $M o$.

${ }^{99}$ Esta interpretación que proponemos salva la contradicción con la solución que encontramos en otros textos que tratan de supuestos similares de servus fructuarius que estipula ex operis alteri eorum (Neracio), ex re alterius (Ulpiano), o expeculio de uno de los cousufructuarios (Paulo).

${ }^{100}$ Conocida es la discusión acerca de la equiparación entre iussum y nominatio y la distinta opinión que sabineanos y proculeyanos mantuvieron al respecto

101 et del. edd. 
pertinet, Sabinus ait, quoniam soli102 obligatus esset, videndum esse, quemadmodum alter usuarius partem suam recipere possit, quoniam inter eos nulla communio iuris esset. sed verius est utili ${ }^{103}$ communi dividundo iudicio inter eos agi posse".

Se trata de una estipulación hecha por el esclavo sobre bienes comunes a los dos usufructuarios, pero con la peculiaridad de estipular nominatim a favor de uno de ellos. Precisamente porque se menciona de forma expresa a uno de los cousufructuarios, Sabino afirma con meridiana claridad que la obligación nace sólo a favor del expresamente nombrado. De nuevo nos encontramos con las mismas consecuencias atribuidas al iussum, por tanto, ante un cambio de régimen jurídico con el consiguiente perjuicio patrimonial para uno de los usufructuarios que, en rigor, no parece tener justificación. Probablemente, ante la falta de argumentos capaces de justificar el enriquecimiento injusto, la jurisprudencia se vio en la necesidad de ofrecer un remedio procesal a quien sufría el quebranto patrimonial. En esa línea de pensamiento el pasaje que nos ocupa trata de la acción para la que estaría legitimado el usufructuario no mencionado en la estipulación: se trataría -dice el texto de Paulo- de la actio communi dividundo utilis.

d) Antes de examinar con detalle la cuestión procesal planteada en D. 45,3,32, sigamos con las consecuencias de estipular nominatim a favor de uno de los cousufructuarios o con el iussum de uno de ellos.

En el siguiente fragmento, a diferencia de los anteriores, se estipula, no sobre bienes comunes, sino ex re alterius: D. 7,1,25,6 (Ulp., 18 Sab.): “Si duos fructuarios proponas et ex alterius re servus sit stipulatus, quaeritur, utrum totum an pro parte, qua habet usum fructum, ei quaeratur. nam et in duobus bonae fidei possessoribus hoc idem est apud Scaevolam agitatum libro secundo quaestionum ${ }^{104}$, et ait volgo creditum rationemque hoc facere, ut si ex re alterius stipuletur, partem ei dumtaxat quaeri, partem domino: quod si nominatim sit stipulatus, nec dubitari debere, quin adiecto nomine solidum ei quaeratur. idemque ait et si iussu eius stipuletur, quoniam iussum pro nomine accipimus. idem et in fructuariis erit dicendum, ut quo casu non totum adquiretur fructuario, proprietatis domino erit quaesitum, quoniam ex re fructuarii quaeri ei posse ostendimus.

La controversia del fragmento es si el usufructuario propietario de los bienes sobre los que estipula el servus fructuarius, adquirirá el total de lo estipulado, o adquirirá sólo la parte correspondiente a su cuota de usufructo. Para resolverla, Ulpiano trae a colación el parecer de Escévola a propósito de dos poseedores de buena fe. A su juicio, es opinión general y razonable que cuando se estipule con bienes de unos de ellos (ex re alterius), se adquiera para éste sólo una parte, mientras que el resto, podrá reclamarlo el verdadero dueño. Este régimen general, no opera, primero, cuando se estipula nominatim, y segundo, por analogía con el anterior, cuando medie iussum, en cuyo caso, legitimado para el ejercicio de la actio ex stipulatu por el total, será el sujeto a favor de quien expresamente se

102 nominatio promissor ins. Mo.

${ }^{103}$ utile $F$.

${ }^{104}$ El caso del que sirve de buena fe a dos dueños aparece en D.41,1,23,3, pero sin la referencia al servus fructuarius. 
estipula (nominatim), o quoniam iussum pro nomine accipimus ${ }^{105}$. Tras este excursus, Ulpiano retoma el supuesto de dos usufructuarios para ofrecer la siguiente regla: cuando uno de los usufructuarios no pueda adquirir íntegramente, la parte que queda vacante la adquirirá el nudo propietario ${ }^{106}$.

El texto implícitamente recuerda el régimen de adquisición en el usufructo -a éste, como veíamos, le corresponde lo adquirido por el servus ex re fructuarii, mientras que al nudo propietario le corresponderán las adquisiciones ex re dominii, ex re fructuarii o aliunde-, y de manera explícita también se refiere al régimen de adquisición por cuotas en los casos de co-usufructo.

El régimen de adquisición se aplica en tanto no medie autorización o no estipule el esclavo expresamente a favor de uno de los usufructuarios. Quiere ello decir que, cuando no sean comunes los bienes, y cuando el servus estipule sin más, queda vacante una parte que, en ningún caso, puede reclamar quien no es propietario de los bienes sobre los que se estipula, es decir, el otro usufructuario, porque para él se trataría de una adquisición ex re dominii o, sin más, aliunde. Esa parte es la adquirida por el nudo propietario ya que a éste, como hemos visto, nada le impide adquirir ex re fructuarii.

Como el eje central del discurso de Ulpiano trata de la adquisición de la parte que no puede adquirir el usufructuario no propietario, parece lógico que no se pronunciara sobre el posible ejercicio de acciones cuando medie autorización, o cuando se estipule expresamente, contra el que experimentó un incremento patrimonial.

e) Queda comprobado que tanto la nominatio como el iussum alteran el régimen inicial previsto para las adquisiciones. Cuestión distinta es si se trata de una alteración real o no.

A este interrogante puede contestarse examinando el remedio procesal previsto en D. 45,3,32.

Aunque Bretone considera que D. 45,3,32 es "affidante" en su conjunto ${ }^{107}$, lo cierto es que el fragmento ha recibido numerosas críticas desde el punto de vista formal, entre otros las de Albertario y Biondi ${ }^{108}$. Ambos coinciden en considerar

${ }^{105}$ La misma idea de equiparación de la nominatio y el iussum, a propósito del servus communis en D. 45,3,7,1 (Ulp., 48 Sab.): "sed si iussu unius socii stipulatus est, idem iuris est, quod esset, si eidem illi socio nominatim dari stipulatus esset". Un estudio detallado de las cuestiones controvertidas que plantean iussum y nominatio, en LAzO, Patricio, "Iussum" y "nominatio" en las adquisiciones a través de dependientes, en REHJ., 31 (2009), pp. 141 ss.

${ }^{106}$ Duda de la opinión que se impuso, Kuntze, Johannes E., cit. (n. 94), pp. 56 ss.

${ }^{107}$ A su juicio, sólo la frase quoniam soli obligatus esset es defectuosa, BrETONE, Mario, La nozione romana di usufrutto, I: Dalle origini a Diocleziano (Napoli, 1962), pp. 92 ss.

${ }^{108}$ Entre otros, BIONDI, Biondo, La legittimazione processuale nelle azioni divisorie romane, en Scritti giuridici (Milano, 1965), II, pp. 696 ss.; y AlberTARIO, Emilio, Studi di diritto romano, IV: Eredità e processo (Milano, 1946), pp. 175 ss., consideran interpolada la frase sed verius-fin. Además de razones formales, la decisión -considera BIONDI- no puede atribuirse a un jurista clásico porque la acción a la que se estaría refiriendo Paulo tenía como única finalidad regular el quemadmodum utantur fruantur sin hacer referencia a las prestaciones. Se pronuncia en contra de esta opinión Riccobono, Salvatore, Dal diritto romano classico al diritto moderno (a proposito di D. 10,3,4 (Paul., 3 ad Plaut.), en Annali Palermo, 3-4 (1917) p. 230 n. 3. 
interpolada la frase sed verius-fin, porque en otras razones-argumenta Biondi- la decisión de legitimar con la actio communi dividundo utilis no puede atribuirse a un jurista clásico.

Formalmente, sorprende que Paulo comience hablando de dos usufructuarios (cum duorum usus fructus esset in servo), y al tratar de la opinión de Sabino aparezca un alter usuarius en lugar de un alter usufructuarius. No obstante, aunque para lo que nos ocupa no es ésta una cuestión determinante, no debe olvidarse que el régimen del usufructus es muy parecido al del usus; nada tendría entonces de extraño entenderlo como un simple error.

De acuerdo con el planteamiento clásico entre los varios titulares del derecho de usufructo no se da una situación idéntica a la prevista para el servus communis, de ahí que, en rigor, los cousufructuarios no estuvieran legitimados para el ejercicio de la actio communi dividundo ${ }^{109}$, aunque en otros pasajes de las fuentes se recuerde el ejercicio de una acción parecida a la acción divisoria ${ }^{110}$.

Como decimos, son numerosos los autores que se han ocupado de D. 45.3.32, pero quizá sea Santoro quien se ha mostrado más crítico con la legitimación para el ejercicio de la actio communi dividundo. A su juicio, la única acción ejercitable sería la condictio, puesto que la acción divisoria sólo prospera cuando la pretensión se ciñe a dividir cosas corporales: división y adjudicación -concluye- sólo son posibles en las cosas corporales ${ }^{111}$.

Disiente de esta opinión A. d'Ors. Para avalar su desacuerdo con la teoría propuesta por Santoro recuerda que la condictio no la mencionan ni Sabino ni Paulo D. 45,3,32, por lo que -añade- no hay razón para pensar que los compiladores, partidarios de utilizar la condictio como remedio general contra el enriquecimiento injusto, la eliminarán del fragmento e introdujeran en su lugar la acción divisoria ${ }^{112}$.

Parece claro que el no respetar el régimen de atribución por cuotas, produce un perjuicio para el usufructuario sobre cuyos bienes también se estipula, aunque no se haga a su favor. El perjuicio sufrido introduce el problema del reparto de lo adquirido, ya que el fructus, como es sabido, es divisible, pero no el usus, porque la

${ }^{109}$ BIONDI, Biondo, recuerda que los clásicos jamás hablaron de communio en el usufructo (cit. n. 108), p. 693. Idea de ausencia de “comunidad” que, como admite también, BRETONE, Mario, cit. (n. 107), pp. 92 ss., es válida para la jurisprudencia clásica, aunque no descarta que los juristas clásicos extendieran al usufructo la idea de la communio.

${ }^{110}$ D.7,1,13,3 (Ulp., 18 Sab.). En casos de controversia entre los co-usufructuarios, la acción divisoria también se concede en vía útil, como en D.10,3,7,7 (Ulp., 20 ed.). Estos ejemplos, y otros más recogidos en la compilación justinianea, son un ejemplo, como recuerda BIONDI, Biondo, cit. (n. 108), p. 687, de la extensión de la acción divisoria a las servidumbres prediales, el uso, el usufructo, la enfiteusis, la fiducia, la prenda y la posesión.

${ }^{111}$ Para apoyar su argumento invoca las palabras recogidas en D.10,3.4 pr. (Ulp., 19 ed.): "Per hoc iudicium corporalium rerum fit divisio, quarum rerum dominium habemus, non etiam hereditatis". SANTORO, Raimondo, cit. (n. 53), pp. 261 ss. Se pronuncian en contra, entre otros, Bretone, Mario, cit. (n. 107), pp. 92 ss. y D'Ors, Álvaro - BONET, Juan Antonio, El problema de la división del usufructo (Estudio romano-civilístico), en Anuario de Derecho Civil, 5 (1952), pp. 74 ss., para quien las palabras de Ulpiano aparecen "sobrecargadas por obra, probablemente, de un glosador tardío”, añadiendo que la acción divisoria sólo se ejercita para pedir la división de la propiedad.

${ }^{112}$ D’Ors, Álvaro, Sobre la supuesta cit. (n. 60), pp. 20-21. 
actividad del esclavo es global. La idea de reparto es la invocada por Biondi para afirmar que, en tiempo de Juliano, se introdujo una acción útil con la finalidad de regular el disfrute de la cosa usufructuada entre varios usufructuarios; acción que tuvo, a su juicio, una estructura distinta a la actio communi dividundo al no suponer ni la división ni la adjudicación del derecho de usufructo ${ }^{113}$. La actio communi dividundo tiene como finalidad, como recuerda A. d'Ors, además de la división de la cosa común, la finalidad de liquidar las relaciones pendientes entre comuneros, aunque los juristas romanos no admitieran su ejercicio para resolver los conflictos entre los cousufructuarios ${ }^{114}$.

Como se ve, la alteración del régimen no es real. Puede que en un primer momento los textos reflejen la transcendencia reconocida a iussum y nominatio, pero sus consecuencias, aunque admitidas en primer momento, no permite desvirtuar el contenido del derecho real de usufructo.

6. La estipulación del servus fructuarius fugitivus o del servus sobre el que un tercero adquiere la posesión.

D. 7,1,12,3 [= FV. 89] (Ulp., 17 Sab.): "De illo Pomponius dubitat, si fugitivus, in quo meus usus fructus ${ }^{15}$ est, stipuletur aliquid ex re mea $^{116}$ vel per traditionem ${ }^{117}$ accipiat: an per hoc ipsum, quasi utar, retineam usum fructum? magisque admitti retiner ${ }^{118}$. nam saepe etiam si praesentibus servis non utamur, tamen usum fructum retinemus: ut puta aegrotante servo vel infante ${ }^{119}$, cuius operae nullae sunt, vel defectae senectutis homine ${ }^{120}$ : nam et si agrum aremus, licet tam sterilis sit, ut nullus fructus nascatur, retinemus usum fructum ${ }^{121}$. Iulianus tamen libro trigensimo quinto digestorum scribit, etiamsi non stipuletur quid servus fugitivus ${ }^{122}$, retineri tamen ${ }^{123}$ usum fructum: nam qua ratione, inquit, retinetur a proprietario ${ }^{124}$ possessio, etiamsi in fuga servus sit, pari ratione etiam usus fructus retinetur" 125 .

En el marco de la extinción del derecho de usufructo por desuso durante los plazos de la usucapión Ulpiano, siguiendo a Pomponio, se pregunta si acaso la estipulación ex re fructuarii del servus fructuarius fugitivus interrumpe el desuso y evita la extinción del usufructo. A juicio de Pomponio, esa estipulación es suficiente para conservar el usufructo y, para avalar su respuesta, añade la analogía

${ }^{113}$ BIONDi, Biondo, cit. (n. 108), p. 693.

${ }^{114}$ D’Ors, Álvaro, Problema cit. (n. 111), pp. 76-77. Se adhiere a esta opinión FERNÁNDEZ BARreIro, Alejandrino, La actio communi dividundo utilis, en Estudios en homenaje al Prof. Santa Cruz Teijeiro (Valencia, 1974), p. 283.

${ }^{115}$ usus fructum meus en FV. 89.

${ }^{116}$ ex re mea om. en FV. 89.

${ }^{117}$ per traditionem ] mancipio en FV. 89.

${ }^{118}$ retineri en FV. 89.

${ }^{119}$ egrotante servo infante FV. 89; aegrotanti vel infante F.

120 homini $F$.

${ }^{121}$ usum fructum] eum en FV. 89.

122 intra annum mancipiove accipiat ins. en FV. 89.

${ }^{123}$ tamen retineri en FV. 89.

${ }^{124}$ proprietario] proprietatis domino en FV. 89.

${ }^{125}$ retinetur] non amittitur en FV. 89. 
con los casos de esclavos que estando presentes (praesentibus servis), no se usan por razones varias (de edad o de enfermedad), y, no obstante, se conserva el usufructo igual que se conserva cuando "agrum aremus, licet tam sterilis sit, ut nullus fructus nascatur". Para Juliano -cuyo parecer nos recuerda Ulpiano y que contradice la opinión de Pomponio- se conserva el usufructo aunque el esclavo fugitivo no estipulara, por una razón semejante -añade Juliano- por la que el dueño conserva la posesión de esclavo aunque éste esté fugitivo ${ }^{126}$.

Una variante de servus fructuarius estipulante o adquirente por traditio se examina en el fragmento siguiente al anterior. En D. 7,1,12,4 se trata también de un servus fructuarius, pero que, en este caso, es poseído por una persona distinta del dominus ${ }^{127}$ : "Idem tractat: quid si quis possessionem eius nactus sit, an, quemadmodum a proprietario possideri desinit, ita etiam usus fructus amittatur? et primo quidem ait posse dici amitti usum fructum, sed licet amittatur, tamen dicendum, quod intra constitutum tempus ex re fructuarii stipulatus est, fructuario adquiri potest ${ }^{128}$. per quod colligi posse dici, ne quidem si possideatur ab alio ${ }^{129}$, amitti usum fructum, si modo mihi aliquid stipuletur, (parvique referre, ab herede possideatur vel ab alio cui hereditas vendita sit vel cui proprietas legata sit, an a praedone): sufficere enim ad retinendum usum fructum esse affectum retinere volentis et servum nomine fructuarii aliquid facere: quae sententia habet rationem".

Aunque tanto Juliano como Pomponio aparecen citados en el fragmento anterior, por razón de proximidad, el idem con el que comienza el texto habría que referirlo a Juliano, y no a Pomponio. Cuando el servus es poseído por un tercero, el dueño pierde la posesión y, en sentido estricto, también el usufructuario perdería su derecho, pero, a juicio de Juliano, eso no impide que el usufructuario adquiera cuando el servus fructuarius estipule ex re fructuarii mientras dure el usufructo. De esta afirmación, Juliano establece como regla general que el usufructuario no pierde

${ }^{126} \mathrm{El}$ mismo problema parece plantearse, al menos en otro texto, a propósito de la propiedad y el usufructo de un fundo. En D.43,16,10 (Gai.. 2 ed. praet. urbani tit. de liberali causa) examina el caso de un praedo que se apodera de un fundo gravado con un derecho de usufructo, y éste deja de utilizarse durante el plazo de duración establecido, el usufructo se extingue y revierte al nudo propietario, aunque no el derecho de propiedad: "Si de fundo proprietarium et fructuarium praedo expulerit atque ob id fructuarius constituto tempore non usus perdiderit ius suum, nemo dubitat, quin dominus, sive experiatur [experitur $\mathrm{F}^{2}$ ] cum fructuario adversus praedonem sive non experiatur, retinere debeat reversum ad se usum fructum et, quod fructuarius perdidit, id ad damnum eius pertineat, cuius facto periit". LENEL, EP. ${ }^{3}$, p. 383 n.2, conjetura que el caso tratado tuviera, en el contexto originario de la obra gayana, finalidad analógica. Para una crítica detallada, véase, MARrone, Mateo, La posizione possessoria del nudo proprietario nel diritto romano, en Ann. Palermo, 28 (1961), p. 54; Santaluccia, Bernardo, L'opera di Gaio ad edictum praetoris urbani (Milano, 1975), pp. 174 ss.

${ }^{127}$ Aunque en ningún momento se habla expresamente de él, la doctrina se ha cuestionado que, como en el fragmento anterior, también se esté tratando de un servus fugitivus. Entiende que sí lo hace, Nicosia, Giovanni, L'acquisto del possesso mediante i "postestate subiecti” (Milano, 1960), pp. 434 ss. En contra, Longo, Giovanni, cit. (n. 40), pp. 466 ss. No se pronuncia sobre esta cuestión, limitándose sólo al examen de la cuestión de fondo analizada en los dos parágrafos, Zamorani, Pierpaolo, "Possessio" e “animus" (Milano, 1977), pp. 97 ss.

${ }^{128}$ potest del. Mo.

${ }^{129}$ alio $F^{a}$ cum B $\Sigma$, eo $F^{b} S$. 
su derecho en tanto conserve la voluntad de mantener el usufructo y, además, el servus fructuarius estipule a favor del usufructuario, o servum nomine fructuarii aliquid facere, el derecho de usufructo no se extingue. Se extinguiría el derecho de usufructo cuando el servus fructuarius estipule con bienes cuya titularidad no sea ex re fructuarii, o cuando estipule a favor de un sujeto distinto al usufructuario.

Los dos fragmentos tratan de la posible pérdida de la titularidad del derecho de usufructo -en este sentido nada significativo aportan sobre el régimen de adquisiciones de la acción que surge de la estipulación-, sin embargo, es de subrayar que la conservación del derecho de usufructo se subordina al hecho de estipular ex re fructuarii, aunque no se mencione en la pregunta estipulatoria a un sujeto concreto.

La solución que ofrecen los pasajes transcritos encaja con el régimen aplicable a las estipulaciones ex re fructuarii a favor de su usufructuario, y que, en definitiva, son una muestra más de la clara tendencia a resolver a favor del usufructuario en las situaciones en las que, originariamente, la adquisición correspondía al nudo propietario.

\section{BiBLIOGRAFÍA}

Grosso, Giuseppe, Usufrutto e figure affini nel diritto romano (2a edición, Torino ,1958). LONGO, Giovanni, Concetto e limiti dell'obbligazione naturale dello schiavo nel diritto romano, en SDHI., 16 (1950).

Burdese, Alberto, La nozione classica di naturalis obbligatio (Torino, 1955).

SCHERILlo, Gaetano, Sulla stipulazione del servus e del filiusfamilias, en Studi Bonfante (Milano, 1930), IV.

Santoro, Raimondo, Per la storia della condictio, en Annali Seminario Giuridico Universitá Palermo, 32 (1971).

SAnfILIPPO, Cesare, “Odium fructuarii", en Studi Volterra (Milano, 1971), IV.

Kaser, Max, La classicità di Gaio, en Gaio nel suo tempo, en Atti del Simposio Romanistico (Napoli, 1966).

D’Ors, Álvaro, La formación del "ius novum" en la época tardo-clásica, en REHJ. 4 (1979).

Bonfante, Pietro, Corso di diritto romano (Milano, 1972), III.

D’Ors, Álvaro, Sobre la supuesta condictio sin datio, en Ivra, 25 (1974).

Donatuti, Guido, Le causae delle condictiones, en Studi di diritto romano (Milano, 1977), II.

CARDILli, Riccardo, La nozione giuridica di fructus (Napoli, 2000).

Buckland, William, The Roman Law of Slavery: The Condition of the Slave in Private Law from Augustus to Justinian (Cambridge, 1908).

ESPINOSA, Thea, En torno a la "stipulatio" y las adquisiciones "in pendenti" por parte del "servus fructuarius", en SDHI., 54 (1988).

Cugia, Stanislao, L"'adiectus solutionis causa" (Napoli, 1919).

KunTZE, Johannes E., Der "servus fructuarius" des römischen Rechts (Leipzig, 1889).

Lazo, Patricio, "Iussum" y "nominatio" en las adquisiciones a través de dependientes, en REHJ., 31 (2009). 
Bretone, Mario, La nozione romana di usufrutto, I: Dalle origini a Diocleziano (Napoli, 1962).

BIONDI, Biondo, La legittimazione processuale nelle azioni divisorie romane, en Scritti giuridici (Milano, 1965), II.

Albertario, Emilio, Studi di diritto romano, IV: Eredità e processo (Milano, 1946).

Riccobono, Salvatore, Dal diritto romano classico al diritto moderno (a proposito di $\mathrm{D}$. 10,3,4 (Paul., 3 ad Plaut.), en Annali Palermo, 3-4 (1917).

d'Ors, Álvaro - Bonet, Juan Antonio, El problema de la división del usufructo (Estudio romano-civilístico), en Anuario de Derecho Civil, 5 (1952).

Fernández Barreiro, Alejandrino, La actio communi dividundo utilis, en Estudios en homenaje al Prof. Santa Cruz Teijeiro (Valencia, 1974).

Marrone, Mateo, La posizione possessoria del nudo proprietario nel diritto romano, en Ann. Palermo, 28 (1961).

SANTAluCCIA, Bernardo, L'opera di Gaio ad edictum praetoris urbani (Milano, 1975).

Nicosia, Giovanni, L'acquisto del possesso mediante i "postestate subiecti” (Milano, 1960).

Zamorani, Pierpaolo, "Possessio" e "animus" (Milano, 1977). 
